\title{
الضوابط النظاهية
}

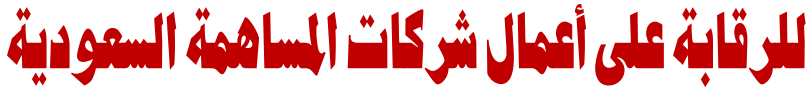

إعداد

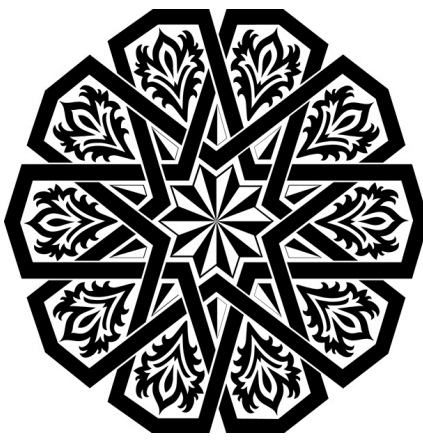

د. نايف بن ناشي الغنامي

أستاذ مساعد - قسم الأنظمة - كلية الشريعة والأنظمة

جامعة الطائف - المملكة العربية السعودية ( الرياض )

\section{موجز عن البحث}

تعد الشركات السعودية المسـاهمة مؤسسـات اقتصـادية وماليـة واجتماعية، وبالتالي

فإن النظام يلعب دوراً هامًا في تنظيم إجراءاتها، وأعمالها وإدارتها ومسئولياتها.

فهي تقوم على استثمار الأموال دون الحاجـة إلى وجـود أصسحابها ممـا يسمح لكثير

منهم احتفاظهم بعملهم الأصلي.

وقد أولت المملكة العربية السعودية عناية كبيـرة بهذا النوع مـن الشـركات وكل مـا

يتعلق بها من أحكام ولم يقتصر الأمر عند هذا بل شملت المراحل اللاحقة لقيام الشركة

وممارستها لنشاطها.

ووضعت المملكـة العربيـة السعودية للشـركات المسـاهمة نوعين مـن الرقابـة وهمـا

الرقابة الداخلية والرقابة الخارجية، وهذا ما سوف أتناوله في موضسوع بحثي "الضـو ابط

النظامية للرقابة على أعمال الشركات المساهمة السعودية" 


\section{Systemic Controls \\ To control The activities Of Saudi Joint Stock Companies \\ Nayef Bin Nashi El- Ghannamy \\ Department Of Law - College Of Sharia And Law \\ Taif University - Saudi Arabia (Riyadh) \\ Email of corresponding author : n.nashi@tu.edu.sa}

Abstract:

The shareholding companies are an economic, financial and social institution; therefor legislations play an important role to organizing its operations, management and responsibilities.

The shareholding companies are in fact based on investment of money, without the owners of that money, which allow investors to be participate in shareholding companies with keeping their own jobs.

The Saudi legislation had attention to the shareholding companies, and all its related provisions, not only at this stage, but also included the later stages of establishment of shareholding companies and its activity.

The Saudi regulator had subjected to the shareholding companies in two types of control, internal control and external control, which I will address in the topic of "regulatory system to control the activities of the Saudi shareholding companies". Keywords :

Commercial Law, Corporate Law, Joint Stock Companies, Statutory Control, Internal Control, External Control, Commercial Law, Statutory Controls, Joint Stock Company Business. 


\section{المقدمة}

تلعب الشركات المساهمة دوراً هامَّ وأساسيًّ في الحياة الاقتصادية وتعول عليها الحكومات الكثير في تنفيذ خططها الاقتصادية وخاصة الخطط طويلة الأمد لما له من قوة بشرية ورأس مال وفير يساعد على إنجاح هذه الخطط بالشكل الأمثل، حيث تقوم الشركات المساهمة بالمشروعات الضخمة التي تتطلب رأس مال كبير وخبرات فنية عالية والتي قد يعجز الفرد الو احد عن القيام بها. ولقد أصبحت الشركات المساهمة البنية الأساسية في بناء الاقتصادات العالمية، حيث استطاعت وبقدرة عالية من جمع أموال ضخمة سواء من كبار المساهمين أو من صغار المساهمين الذين يسعون إلى استثمار أموالهم بالإضافة إلى تحديد مسؤولياتهم عن ما قد يحدث من ديون للشركة بقدر حصصهم في رأس مال الشركات المساهمة. ولذلك أولى المنظم في المملكة العربية السعودية منذ منتصف القرن الماضي الاهتمام بالتطور في الشركات المساهمة وذلك بإصدار نظام الشركات الصادر بالمرسوم الملكي رقم (7) لسنة 970 (م، ونظام الشركات الصادر بالمرسوم الملكي

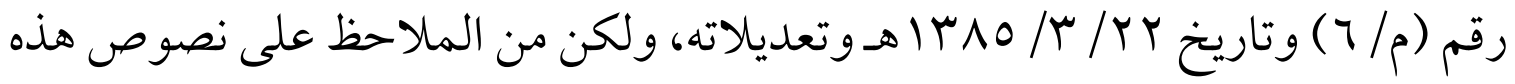
الأنظمة أنها كانت قاصره ولم تستطع القيام بسد حاجات الشركات المساهمة ولذلك كثرت القرارات الصادرة من مجلس الوزراء لسد العجز الحاصل في هذه الأنظمة. وتلى ذلك إصدار الأوامر السامية لتعديل نظام الشركات السعودي القديم والعديد من القرارات الوزارية في هذا الشأن إلى أن صدر نظام الشركات السعودي الجديد الصادر عام Y V أهـ ، الذي قام بتلافي أخطاء المنظم في نظام الشركات السابق وما تلاه من قرارات وزارية، وأسبغ الحماية الكاملة على كافة أنواع الشركات بصفة عامة، 


\section{وشركات المساهمة بصفة خاصة، والرقابة على أعمالهم.}

وعليه ووفقـا لما سبق سرده، ولمزيد من الحماية الكاملة وإحكام الرقابة على

أعمال شركة المساهمة لم يقف المنظم في المملكة العربية السعودية مكتوفي الأيدي أمام العديد الظواهر السلبية وغيرها من التي تمس كيان الشركات المساهمة والتي من شأنها الأضرار بالكيان المادي والاقتصادي للشركة، وأخضع شركات السماهمة لنوعين من الرقابة، أولاً الرقابة الداخلية يضطلع ويقوم بها مجموع المساهمون ومر اجعوا الحسابات، والرقابة الخارجية تباشرها الجهات الإدارية المختصة، وهي هيئة السوق المالية، وإدارة الشركات، وهو ما سوف أتناوله بالتفصيل من خلال ورقات

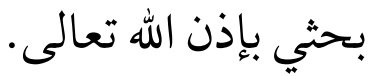




\section{المبحث التمهيدي}

\section{ماهية شر كة المساهمة ونشأتها وأركانها}

إن الشركات في النظام السعودي تنقسم بصفة عامة إلى شركات مدنية وشركات

تجارية وما يخصنا هنا هي الشركات التجارية وتنقسم الشركات التجارية على حسب أنظمة المملكة العربية السعودية"(1) إلى شركات تقوم على اعتبارات شخصية وهي تعتمد على المعرفة الشخصية والثقة المتبادلة ما بين الشركاء مثل شركة المحاصة وهي تعتبر من شركات الأشخاص التي تعتمد على المعرفة السابقة بين الشركاء أما القسم الأخر من الشركات التجارية فيعتمد على الأموال فالعبرة هنا الأموال التي تؤسس الشركة ولا عبرة بمن يساهم فيها أو يكون شريكَّ فيها ومنها الشركة المساهمة وهي ما نحن بصدد الحديث عنها هنا.

أيضًا يجب أن يكون لشركة مساهمة اسم يبين الغرض الذي أُنشاءه من أجله، و ألا يكون اسم الشركة مشتمل على اسم شخص طبيعي إلا إذا كانت الشركة تقوم على غرض استخدام براءة اخترع مسجلة باسم شخص طبيعي أو قامت بشر اء شركة تستخدم اسم شخص طبيعي وقامت شركة المساهمة بإتخاذ اسم هذه الشركة اسمَّ لها. أو أن تكون شركة مسجلة باسم شخص طبيعي وتحولت وفقًا للنظام إلى شركة مساهمة فإن اسمها يستمر، وأخيراً إذا كانت شركة المساهمة تحولت ملكيتها إلى شخص ملكية شخص واحد فيجب أن يفيد اسمها بانها شركة مملوكة لشخص طبيعي واحد، هذا ما

(1) نظام الشركات السعودي (الجديد) الصادر بالمرسوم الملكي رقم (م/r) بتاريخ / / / / I إمجري. حيث ألغي نظام الشركات السابق. 
نصت عليه المادة الثالثة والخمسون من نظام الشركات السعودي. ونصت المادة الخامسة والخمسون من نفس النظام على أنه يجوز تأسيس شركة مساهمة من شخص واحد وذلك يكون من قبل الدولة، أو الشركات المملوكة بالكامل للدولة، أو الأشخاص ذوي الصفة الاعتبارية العامة، أو الشركات التي لا يقل رأس مالها عن خمسة ملايين ريال.

وعليه فإننا سنتطرق إلى بيان ماهية شر كات المساهمة من خلال المطالب الآتية: المطلب الأول : مفهوم ونشأة شركة المساهمة. المطلب الثاني: أر كان و أهمية شركة المساهمة. وفقًا للتفصيل الآتي.

\section{المطلب الأول مغهومر ونشأة شركة المساهمة المهاهة}

أولاً: مفهوم شركة المساهمة

إن الشركات المساهمة التي تنشئ في المملكة العربية السعودية تكون خاضعة لنظام الشركات السعودي الذي أشار إلى الشركات المساهمة في الباب الخامس من نظام الشركات السعودي وذكر تعرف الشركة المساهمة في الفصل الأول وبالتحديد المادة الثانية والخمسون حيث نصت المادة سابقة الذكر على أن الشركة المساهمة " شركة رأس مالها مقسم إلى أسهم متساوية القيمة وقابلة للتداول، وتكون الشركة وحدها مسؤولة عن الديون والالتزامات المترتبة على ممارسة نشاطها"(1). ويعتبر هذا التعريف

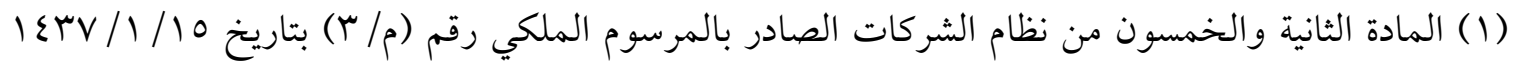
هجري. 
من التعاريف الشاملة التي توضح كيان الشركة المساهمة، ويهدف هذا التعريف إلى معاني عدة وهي أن شركة المساهمة يكون رأس مالها مقسم إلى عدد معين من الأسهم،

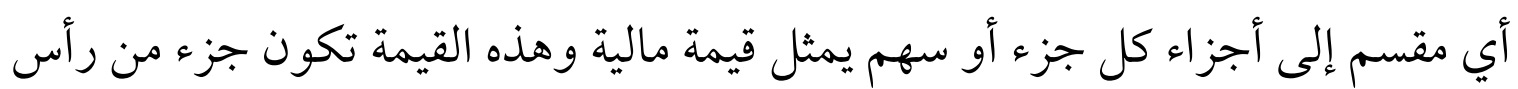
مال الشركة أي أنها لو جمعت هذه الأجزاء أو الأسهم لمثلة رأس مال الشركة. وذكرت المادة السابقة بأن الأسهم متساوية القيمة أي ألا تكون مختلفة في القيمة بمعنى أنه لا يمكن أن يكون هناك سهم في الشركة بعشرة ريالات وسهم أخر بخمسة ريالات فجميع الأسهم يجب أن تكون متساوية القيمة، مثال ذلك لو افترضنا أن رأس مال الشركة هو

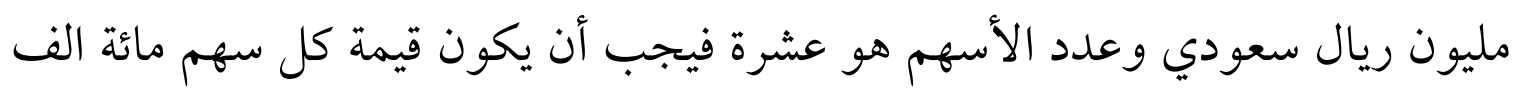
ريال. والأسهم يجب أن تكون قابلة للتداول أي أن تكون قابل للبيع والشراء وعليه يمكن أن يقوم المالك بيع أسهمه ويمكن للغير أن يقوم بشر ائها. ثانياً: نشأة شركة المساهمة إن رأس مال الشركة المساهمة هو الضمان الوحيد للدائنين، وعليه فإنه لا يجوز تقديم حصة عمل في رأس مال الشركة، بل يجب أن تكون الحصص المقدمة في رأس مال الشركة ذات قيمة مالية، وعليه فإن رأس مال الشركة يقسم إلى حصص تسمى لهى أسهم وهذه الأسهم يجب أن تكون متساوية القيمة وتعتبر مجموع هذه الأسهم هي ما يكون رأس مال الشركة الذي يساهم فيه الشركاء، إما أن يكون من مجموعة من

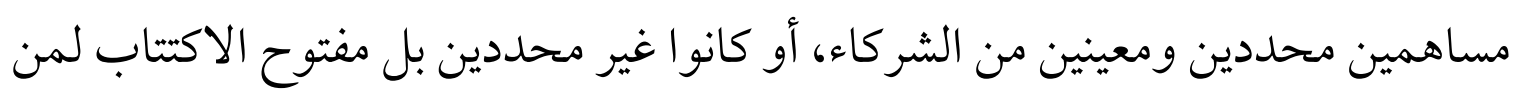
يرغب المساهمة من الجمهور . ويقدر المؤسسون وحدهم قيمة رأس مال الشركة الذي 


\section{يكتفي به لتحقيق الغرض الذي أنشاءه الشركة من أجل تنفيذها.}

ولقد نص نظام الشركات السعودي القديم على أن تكوين رأس مال الشركة المساهمة ينقسم إلى رأس المال المرخص به ورأس مال المصدر. فيكون رأس مال الشركة المرخص به يجب أن يحدد في نظامها وقد يتجاوز رأس مال المصدر الذي يتم الاكتتاب فيه عند تأسيس الشركة. ويجوز لمجلس إدارة الشركة زيادة رأس مال المصدر وتحديد رأس مال المرخص به دون الحاجة إلى تعديل نظام الشركة. وبذلك يسمح هذا النظام لمجلس الإدارة بإصدار قرار بزيادة رأس مال الشركة الذي يجعل الشركة قابلة لتأقلم مع الظروف الاقتصادية المحتملة، وتتفادى عيوب الاكتتاب الكامل في رأس مال الشركة، وتتجاوز بذلك دعوة الجمعية العامة الغير عادية التي تقوم بتعديل نظام الشركة لزيادة رأس المال مما يسبب هدر للوقت و المال والجهد (r). وهذا خلافَّا لما ذكره نظام الشركات السعودي الجديد في نص المادة الثانية والخمسون سالفة الذكر على أنه شركة المساهمة شركة رأس مالها مقسم إلى أسهم متساوية القيمة وقابلة للتداول، وتكون الشركة وحدها مسؤولة عن الديون والالتزامات المترتبة على ممارسة نشاطها. وإضافة إلى ذلك فإن رأس مال الشركة يجب أن يكون كافيًا لتحقيق الغرض الذي أنشاءه من أجله، وعليه فإن المؤسسين هم من يتولون تحديد رأس مال الشركة، إلا أنه

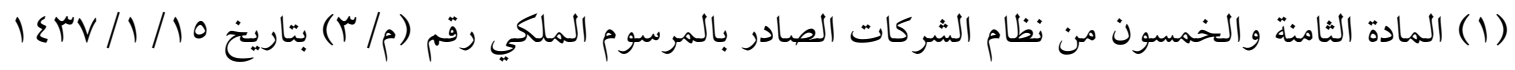
هجري.

(Y) د/ محمد رزق، الرقابة على أعمال شركة المساهمة، بحث منشور بنك المعرفة المصري، المنصورة، 17 • Y، $.1 \mathrm{~V}$ 
يوج بعض القيود الني يجب مراعاة على النحو التالي: ورد نص المادة (9 ع) من نظام الشركات السعودي القديم: هذا النص وفقـَّل لآخر

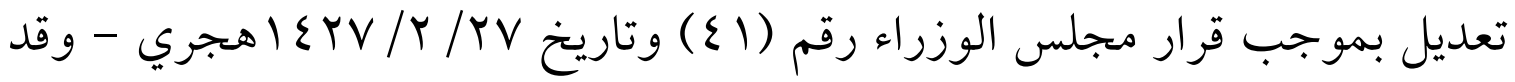

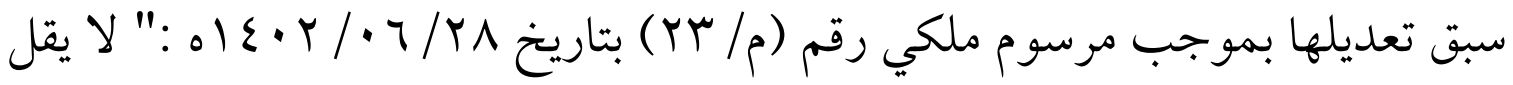
رأس مال شركة المساهمة التي تطرح اسهمها للاكتتاب العام عن عشرة ملايين ريال سعودي وفيما عدا هذه الحالة لا يقل رأس مال الشركة عن مليوني ريال سعودي. ولا يقل المدفوع من رأس المال عند تأسيس الشركة عن نصف الحد الأدنى مع مراعاة ما تقضي به المادة (01) و لا تقل قيمة السهم عن خمسين ريالا سعوديًا".

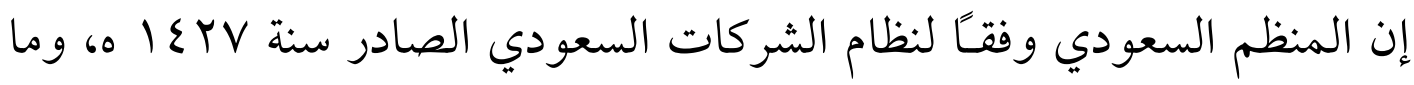
طرأ عليه من تعديلات بعد ذلك جعل هناك شرطَّ لإنشاء شركة المساهمة وهو أن الشركة المساهمة التي تطرح أسهمها للاكتتاب يجب أن يكون الحد الأدنى لرأس مال الشركة هو • إملايين ريال، وألا يقل المدفوع من رأس المال عند تأسيس شركة المساهمة عن نصف الحد الأدنى، وأن لا تقل قيمة السهم الو احد عشرة ريالات"). ويتضمن هذا النص الاشتراك في تأسيس شركات الأموال أو زيادة رأس مالها، ويلاحظ من هذا النص أن يكون مقتصراً على نوع معين من الشركات وهي التي تقوم بالمشروعات الكبرى، ولكن يعيب هذا النص أنه أحد سلبيات النظام القديم الذي تم تلافيه في نظام الشركات السعودي الجديد وهوما سوف نوضحه لاحقـً.

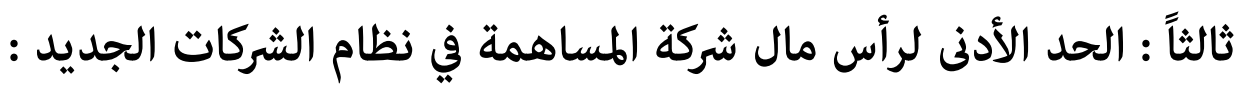

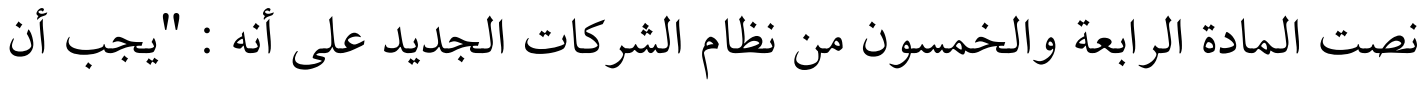

(1) / محمد محمود رزق ، الرقابة على أعمال شركة المساهمة، مرجع سابق، ص 11 . 
يكون رأس مال الشركة عند تأسيسها كافيًا لتحقيق أغراضها، وفي جميع الأحوال لا يجوز أن يقل عن (خمسمائة ألف ريال)، ويجب كذلك ألا يقل المدفوع عن رأس

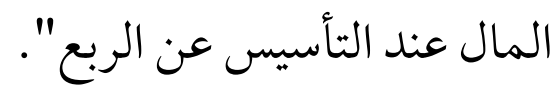
إن الأصل في الشركات المساهمة هو الحرية للمؤسسين لتحديد رأس مال الشركة بما يعود بالمنفعة لها ويحقق الصالح العام للشركة وللمساهمين. ولكن نص النظام على بعض الاستثناءات على الأصل وهو ألا يقل رأس مال الشركة المساهمة عن خمسمائة ألف ريال، وألا يقل المدفوع من رأس المال عند التأسيس عن الربع، ويستنتج من ذلك أن المنظم السعودي قام بتقليل المبلغ المودع إلى خمسمائة ألف رلف ريال لإنشاء الشركة المساهمة عن ما ذكره في النص القديم لتشجيع المستثمرين من الداخل ومحاولة جذب الأموال والاستثمارات من الخارج إلى السوق في المملكة

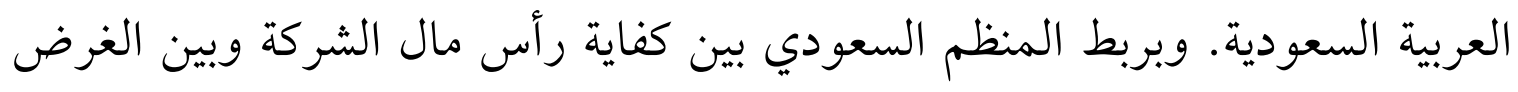
المراد تحقيقه من إنشائها، وبتقليل الحد الأدنى لرأس المال إلى خمسمائة ألف ريال، فقد أحسن في ذلك لرغبته في دخول أكبر قدر ممكن من رؤوس الأموال وتشجيع صغار المستثمرين ويجعل أعمالهم أكثر تنظيمًا وربطها عبر بوابة الشركات المساهمة السعودية.

ونظراً لقانون الشركات السعودي الصادر بالمرسوم الملكي رقم (7) لسنة 1970 وتعديلاته من الأوامر السامية أو القرارات الوزارية، وبمقارنته بنظام الشركات

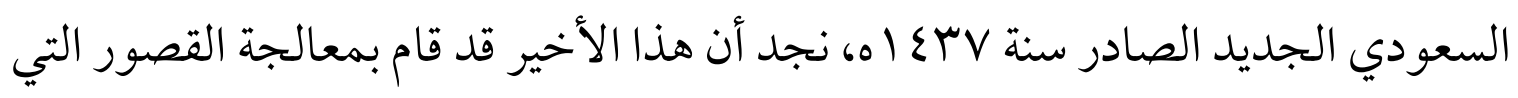
كانت في النظام القديم، ويسد الثغرات المتو اجدة فيه ويعالج مشكلة كثرة تعدد الأوامر السامية والقرارات الوزارية التي سعت إلى معالجة القصور في النظام القديم، ولقد جاء 
النظام الجديد للشركات لمعالجة تلك الجزئيات ومنها مسألة تكوين رأس المال، كما

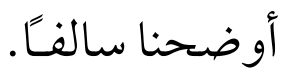

\section{المطلب الثاني \\ أهمية وأركان شركة المساهمة}

أولاً: أهمية شركة المساهمة

إن مزاولة التجارة لا تقتصر على التجار فقط، وإنما تمتد لتمارس في إطار قانوني

من قبل الأشخاص الاعتبارية وهي الشركات. وتقوم هذه الشركات بتجميع مجهودات مجموعة من الأفراد ومدخلاتهم للقيام بأعمال يعجز عن القيام بها الأفراد بمفردهم مهما بلغت قدرتهم. لذلك أصبحت مثل هذه الأعمال الجماعية أكثر اتصالاً بالعمل الجماعي وبتضافر الجهود من قبل الأفراد بالتعاون والاشتراك. ومع التطور الاقتصادي أصبح من الضروري استغلال تجميع رؤوس أموال كبيرة لتحقيق مشروعات تجارية ضخمة من خلال نظام الشركات الذي يحقق للمجتمع مصالح مهمة من نو احي عدة مثل النواحي المالية والقانونية والاجتماعية (1). ثانياً: أركان عقد الشركة

تعتبر شركات المساهمة من الشركات التي تتم عن طريق عقد يلتزم بمقتضاه كل طرفي العقد بمساهمة في الشركة، وهذه المساهمة تهدف إلى تحقيق الربح، وتكون هذه المساهمة عن طريق تقديم كل طرف حصة من مال أو عمل ويقتسم كل طرف ما ينتج عن هذا المشروع من ربح أو خسارة لذلك يجب أن يقوم العقد على الأركان التي يقوم

(1) الدكتور عبدالهادي الغامدي، القانون التجاري السعودي، مجلة الشقيري، الطبعة الثانية، جدة، السعودية،

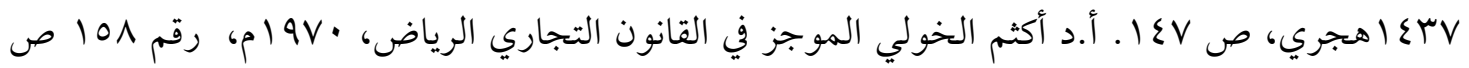


عليها أي عقد وهي الأركان الموضوعية التي تقوم عليها سائر العقود وهي الرضاء والمحل والسبب والأهلية. وكون عقد شركة المساهمة من العقود التي تكون من خلال تصرف قانوني فإن القانونية يلزم بتوفر أركان موضوعية خاصة وهي عدد الشركاء وتقديم الحصص ونية المشاركة واقتسام الأرباح والخسائر بين الشركاء. ويتطلب النظام أيضًا أن تكون هناك شروط شكلية وهي الكتابة وتوثيق عقد الشركة وإشهاره. وبتحقيق الشروط الموضوعية العامة والخاصة والشرط الشكلي يكون العقد بـد صحيح. وتصبح الشركة لها صفة اعتبارية مخاطبة بالقانون. ولكن إذا انعدمت الشروط

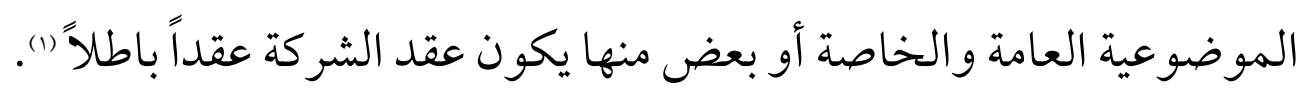
سوف نتطرق لذكر شيء من التفاصيل لكل عنصر من العناصر عناصر الشروط الموضوعية والعامة والخاصة والشرط الشكلي في عقد شركة المساهمة على النحو التالي.

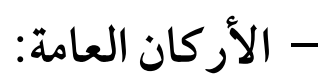
يجب أن يتوفر في عقد شركة المساهمة الأركان العامة التي يقوم عليها عقد الشركة وبالتالي تقوم عليها التصرفات القانونية وهي الرضا والمحل والسبب والأهلية. وسوف نوضح كل عنصر من هذه العناصر على النحو التالي: أولاً: الرضا الرضا هو الصيغة القانونية والتعبير عن إرادة المتعاقدين بالإيجاب والقبول (1) الدكتور عبدالهادي الغامدي، القانون التجاري السعودي، مرجع سابق، ص IVI. 
بالدخول في عقد شركة المساهمة"). وعليه فيجب أن ينصب الرضا على كافة عناصر عقد شركة المساهمة مثل رأس مال الشركة والغرض من قيام الشركة وحصص الشركاء وكيفية إدارة الشركة وجميع ما يتعلق بالشركة.

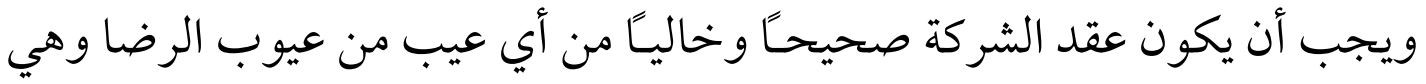
الإكراه والتدليس و الغلط، فالإكراه هو إجبار الشخص على الدخول كمساهمة في شركة المساهمة بغير رضاه وهذا قلما يحدث في شركات المساهمة لأن الدخول فيها يتطلب أكثر من إجراء وأكثر من عملية قانونية ومالية يصعب حدوثها في وقت واحد، وعليه تصعب عمليه الإكراه(") - (") أما التدليس فهو ما قد يقوم به مؤسسو الشركة المساهمة لحمل الغير على الدخول في المساهمة من خلال إظهار معلومات مخالفة للواقع وفي هذه الحالة يكون العقد قابل للبطلان لمصلحة من دُلس عليه("). وأما الغلط المعتبر هنا هو الغلط الجسيم الجوهري الذي يجعل عقد الشركة قابل للبطلان لمصلحة من أُرتكب الغلط في حقه، فالغلط هنا هو الغلط في شخصية الشركة أو غرضها أو أن يكون الغلط في العناصر المهمة في قيام الشركة مثل رأس مال الشركة

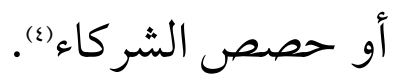

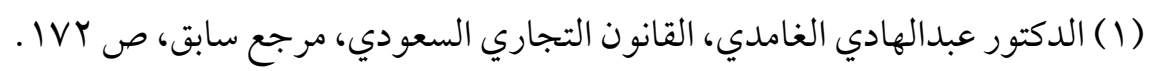

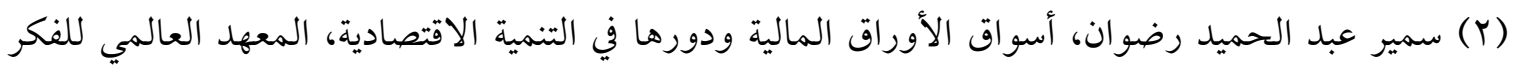

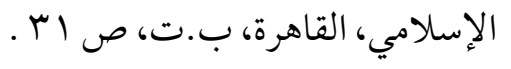

(Y) الدكتور عبدالهادي الغامدي، القانون التجاري السعودي، مرجع سابق، ص IVY ـ .

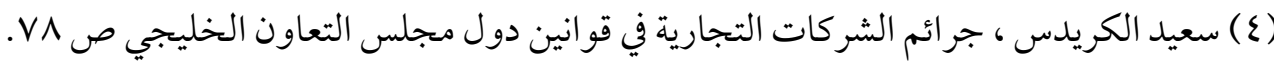




\section{ثانيًا : المحل}

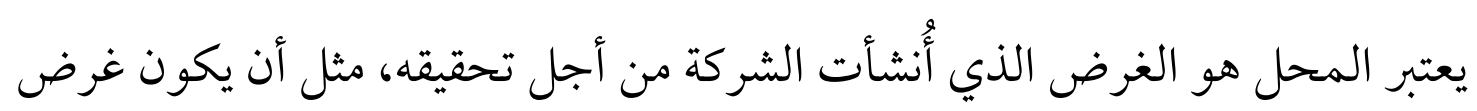

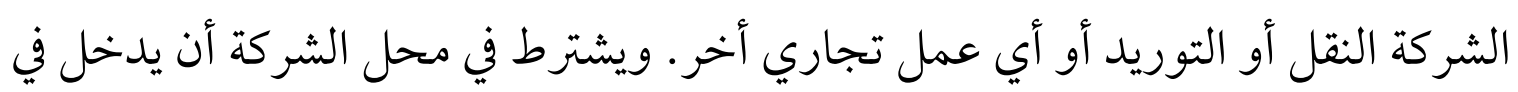

دائرة التعامل أي أن يكون قبل للتعامل به إما بنص قانوني أو بطبيعته وما يخرج عن دائرة

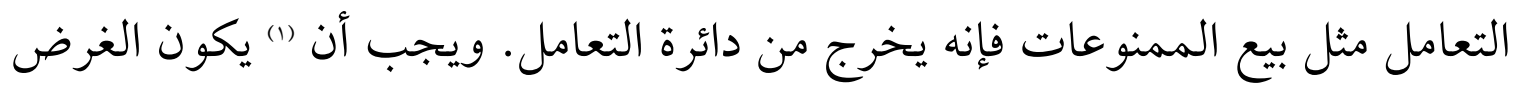

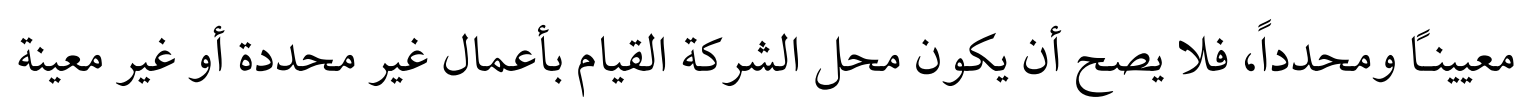

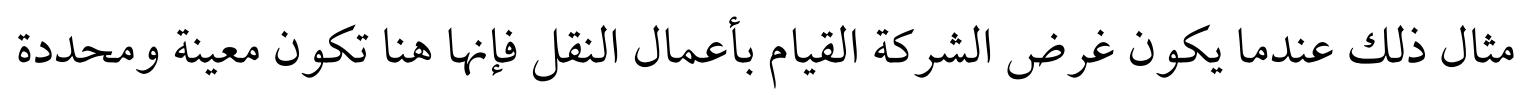
الغرض. ويجب أن يكون غرض الشركة ممكننا أي قابل للتحقيق، وعليه فإذا كان الغرض غير ممكن تكون الشركة قابلة للبطلان فعلى سبيل المثال إذا ألغي امتياز قد فد أعطي للشركة من قبل الحكومة فإن الغرض يكون غير ممكن، أو وقعت قوة قاهرة تمنع قيام الشركة بالعمل المنوط بها فإن الغرض يكون غير ممكن. ويجب أن يكون الغرض

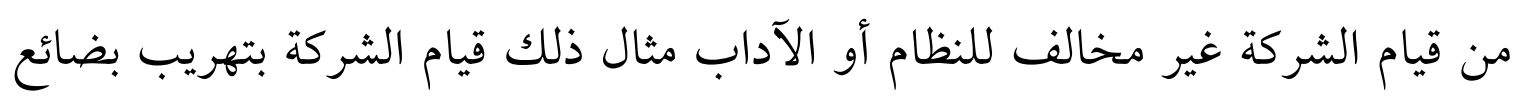
مخالفة للنظام يجعل الغرض مخالف للنظام وتكون هذا الأعمال باطله بقوة النظام. ثالثًا : السبب يعتبر السبب هو الغاية من تكوين الشركة وهو تحقيق الربح وتوزيعه على الشركاء. وبهذا المعنى يكون السبب دائما مشروع. ولا يوجد مجال للخلط بين السبب و المحل كما يعتقد البعض. فالسبب يتحقق بوجود المحل، والمحل هو الطريق لتحقيق السبب.

(1) د/ فوزي عطوى: الشركات التجارية في القوانين الوضعية والشريعة الإسلامية، منشورات الحلبي، لبنان،

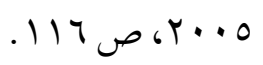


وعليه فإن تحقق الربح كغاية يعد مشروع ولكن قد يكون الطريق إل ذلك غير مشروع مثل التجار بالمخدرات. والعكس صحيح قد تنشأ شركة للقيام بالنقل وهذا العمل مشروع ولكن السبب ليس لتحقيق الربح وإنما للإضرار بالغير، فالمحل هنا مشروع ولكن السبب ليس مشروع. لذلك لا يمكن القول بأن عدم مشروعية السبب يؤدي بالضرورة إلى عدم مشروعية المحل (1).

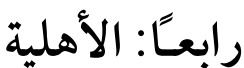

يقصد بالأهلية هي قدرة الشخص على القيام بالتصرفات القانونية، بمعنى أنه لا يكون عقد شركة المساهمة صحيحكً مالم يصدر من أشخاص لهم أهلية التعاقد. لذلك ألك لابد من أن يصدر من أشخاص قادرين على القيام بالتصرفات القانونية، أي أن يكون

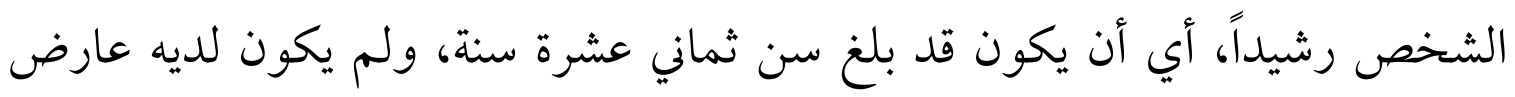
يفقده الأهلية مثل الجنون والعته، أو أن يعتريه عارض ينقص الأهلية مثل الغفلة والسفه، وعليه فإن كان سيلم العقل وبلغ السن النظامي ثمانية عشرة سنة يحق له أن يكون شريكَّ في شركة المساهمة. ويرى البعض أن الأهلية الأزمة للدخول في شركة المساهمة يجب أن تكون أهلية التصرف أي أن تكون التصرفات دائرة بين النفع والضر وهذا ما يتو افق مع الشريعة الإسلامية. فالقاصر يحتاج إلى إذن من وليه لدخول شريك في شركة

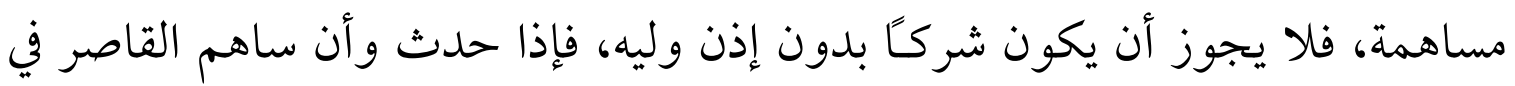
شركة المساهمة فتكون مساهمة كشريك في شركة المساهمة قابلة للبطلان لمصلحة

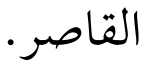

(1) د/ عبدالهادي الغامدي، القانون التجاري السعودي، مرجع سابق، ص ع IV. 


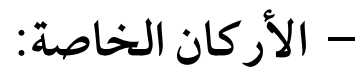

يجب أن يتوفر في عقد شركة المساهمة أركان موضوعية خاصة بالعقد بجانب الأركان الموضوعية العامة. وهي ما يميز عقد الشركة عن غيره من العقود الأخرى. وتتمثل هذا الأركان في تعدد الشركاء وتقديم الحصص ونية المشاركة واقتسام الأرباح والخسائر.

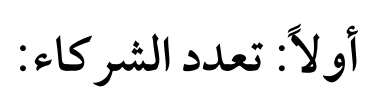

تعدد الشركاء يعتبر هو التعاون والاشتراك في تحقيق مصالح مشتركة بين مجموعة من الأشخاص. وبناء على نص المادة الثانية من نظام الشركات السعودي فإنه يلزم لعقد الشركة وجود شخصين أو أكثر (1. إن هذا النص يتفق مع فكرة العقد التي تقوم على أساس أن الشركة عقد وأن العقد يجب عند إبرامه وجود شخصين أو أكثر فلا يوجد عقد أحادي الطرف. والشركاء هنا قد يكون أحدهم شخص طبيعي و الطرف الأخر شخص معنوي مالم يشترط النظام خلاف ذلك. ونظراً لتعدد الشركاء في الشركة المساهمة فإنه لا يوجد تحديد من قبل النظام للحد الأنى أو للحد الأعلى من المساهمين في الشركات المساهمة. مالم تكن الشركة شركة الشخص الواحد فإنه ينعدم تعدد الشركاء فيها فيكون إما شخص طبيعي أو شخص اعتباري و احد مالكَّ للشركة. وتأخذ شركة المساهمة من شخص واحد شكلين:

(1) المادة الثانية من نظام الشركات لسنة VrV ا هجري نصت على أن "الشركة عقد يلتزم بمقتضاه شخصان أو أكثر بأن يساهم كل منهم في مشروع يستهدف الربح بتقديم حصة من مال أو عمل أو منهما معَّ لاقتسام ما ينشأ

$$
\text { من هذا المشروع من ربح أو خسارة". }
$$


الشكل الأول : أن تكون شركة المساهمة مملو كة بالكامل للدولة. الشكل الثاني : أن يكون رأس مال الشركة لا يقل عن خمسة مليون ريال"(1). الأصل في تكون الشركة المساهمة هو تعدد الشركاء، وهذا ما نصت عليه المادة الثانية من نظام الشركات("). ويستمر تعدد الشركاء طول حياة الشركة فإذا نقص العدد عن شريكين يجب تصحيح وضعها خلال الفترة التي حددها النظام وإلا انقضت الشركة

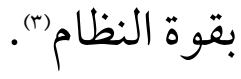
ثانيًاً : تقديم الحصص

يجب أن يقدم كل شريك في الشركة المساهمة حصة تساهم في بناء الشركة سواء أكانت حصة نقدية أو عينية أو عمل. وتعتبر الحصة النقدية والعينية هما ما يمكن أن يدخل في رأس مال الشركة. وتعتبر الحصة النقدية هي ما يقدمه الشريك من أموال نقدية كمساهمة في رأس مال الشركة، والحصص العينية هي ما يقدمه الشريك غير النقود للمساهمة في رأس مال الشركة مثل منقو لات أو عقار أو غيرها مما يمكن تثمينه بالنقد،

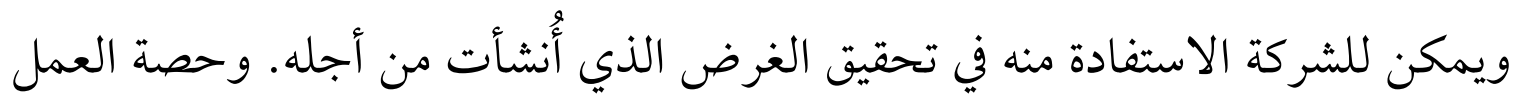
هي ما يمكن أن يقوم به الشرك للشركة من إدارتها وتيسير أعمالها، وهنا لا يمكن تقديرها بالنقد وإنما يكون شريك في الشركة المساهمة مساهمًا بالعمل لمصلحة الشركة، وهذه الحصة التي يقدمها الشريك هي ما تعطيه الحق في الحصول على

(1) انظر نص المادة الخامسة والخمسون من نظام الشركات لسنة لrV ا هجري.

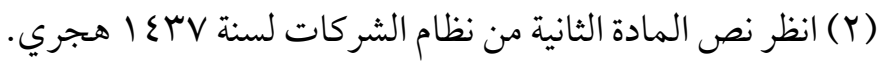

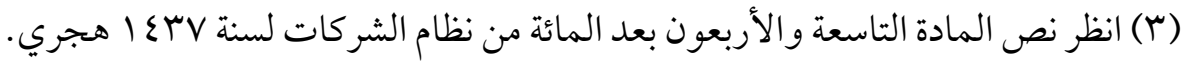


إن الحصص التي يقدمها الشركاء ليست شرطَّا أن تكون من طبيعة واحدة أو أن تكون متساوية في المقدار. لكن يجب أن تقدر الحصص بما يعادلها من قيمة نقدية لكي يتبين نصيب كل شريك في الشركة المساهمة، وبها تحدد نصيب كل شريك في الربح والخسارة. وتنتقل هذه الحصص من ذمة المساهم في شركة المساهمة إلى ذمة الشركة التي يحق لها التصرف بهذه الحصص (r). ثالثًا: نية المشار كة

نية المشاركة يقصد بها الرغبة بين الشركاء على المشاركة والتعاون على تقديم أمو الهم الخاصة لقيام شركة المساهمة وتعرض هذه الأموال للمخاطر . ويستنتج من هذا الركن أنه يبين إرادة أطراف العقد في المشاركة في تكوين الشركة. ولقد نصت المادة الثانية من نظام الشركات(r) على إلزام كل شريك بالمساهمة في مشروع مالي وبهذا النص نستنتج أن تكون هناك نية للمشاركة فلا يتصور وجود اتفاق بين الشركاء على الدخول في تكوين شركة مساهمة بدون وجود نية المشاركة. فلا وجود للتبعية بين الشركاء، وإنما الجميع يكون متساوي في المراكز القانونية. وبناء على ما سبق فإن نية المشاركة بين الشركاء تعد من الأركان الموضوعية الخاصة

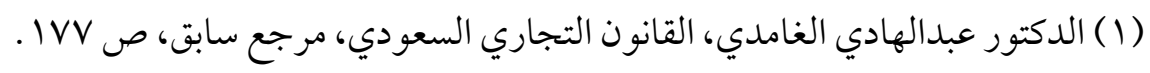

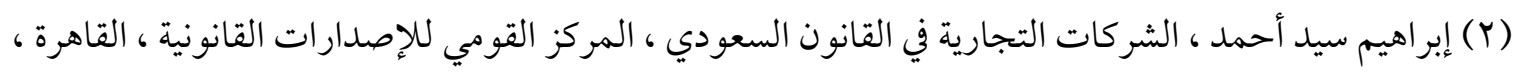

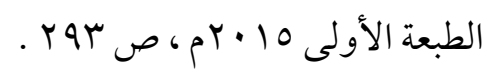

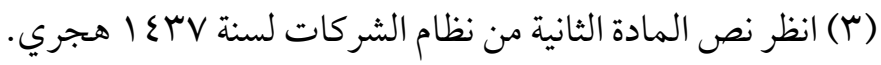


في عقد الشركة التي يؤدي تخلفها إلى بطلان عقد الشركة").

\section{رابعًا: اقتسام الرباح والخسائر}

إن الهدف من تقديم الشركاء للحصص هو تحقيق الربح واقتسامه بينهم. وبما أن الشركة قد تحقق الربح فإنه قد يلحقها خسائر. وعليه فإن الشركاء يتعين عليهم المشاركة في تحمل الخسائر كما يحصلون على الربح الناتج من الشركة. وإن اقتسام الشركاء للربح والخسائر يعد من الأركان الموضوعية لعقد الشركة التي نصت عليه المادة التاسعة من نظام الشركات("). وعليه لقد بينت المادة السابقة الذكر على أن اقتسام الربح والخسائر يكون بنسبة كل شريك في الشركة، لذلك لا يجوز الاتفاق بين الشركاء على حرمان أحد الشركاء من الحصول على الأرباح أو إعفاءه من تحمل الخسائر. ولكن لا يجب أن يكون جميع الشركاء متساوون في الربح والخسائر، وإنما كلاً بحسب أبحن نسبة حصته في رأس مال الشركة").

\footnotetext{
(1 ) إبراهيم سيد أحمد، الشركات التجارية في القانون السعودي، مرجع سابق، ص ه •r. (Y) انظر نص المادة التاسعة من نظام الشركات لسنة كrV إ هجري.

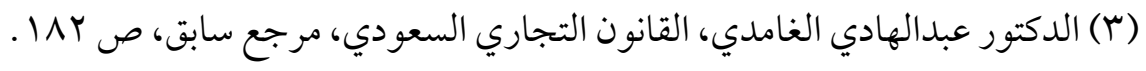




\section{المبحث الأول \\ مسؤولية مجلس إدارة شر كة المساهمة}

سوف نتناول في سياق هذا المبحث مسؤولية مجلس إدارة شركة المساهمة، وذلك من خلال ثلاث مطالب المطلب الأول سوف يتناول مسؤولية أعضاء مجلس الإدارة تجاه الشركة، ثم في المطلب الثاني سوف نتطرق إلى مسؤولية أعضاء مجلس الإدارة تجاه المساهمين، وفي المطلب الثالث مسؤولية أعضاء مجلس الإدارة تجاه الغير.

وذلك من خلال الآتي:

المطلب الأول: مسؤولية أعضاء مجلس الإدارة تجاه الشركة.

المطلب الثاني: مسؤولية أعضاء مجلس الإدارة تجاه المساهمين.

المطلب الثالث: مسؤولية أعضاء مجلس الإدارة تجاه الغير.

\section{المطلب الأول}

وفتًا للتفصيل الآتي بيانه:

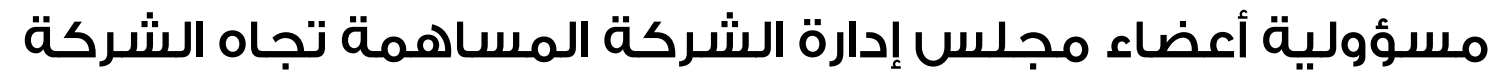
في ظل نظام الشركات السعودي إداري

إن وجود المزايا الحسنة في بعض أعضاء الشركة المساهمة هي العامل المهم الذي

يتم من خلاله اختيار أعضاء مجلس الإدارة، ومع وجود الثقة في بعض أعضاء الشركة جعلت أعضاء الجمعية العامة للشركة المساهمة يقومون بتكليف من توجد بهم الثقة بتسلم مهام أعمال الشركة. وعليه وجب على هؤ لاء الأعضاء أن يقومو ا بالمهام الموكلة إليهم على أكمل وجه، ومن هذه المهام حضور جلسات المجلس على وجه الدوام، وتقديم كل ما يستطيعون من جهد ونشاط في خدمة الشركة، والقيام بكل ما يعود على الشركة من فوائد من خلال مراقبة سير العمل، والمراقبة والإشراف على الموظفين و العمال، وتطبيق نظام الشركة الأساسي، والاهتمام بإمساك دفاتر الشركة، والعمل على 
زيادة أرباح الشركة، والإعداد المسبق لجدول أعمال الجمعية العامة ودعوة الأعضاء للحضور للاجتماع في المواعيد المحددة والمنصوص عليها في نظام الشركة. ويجب

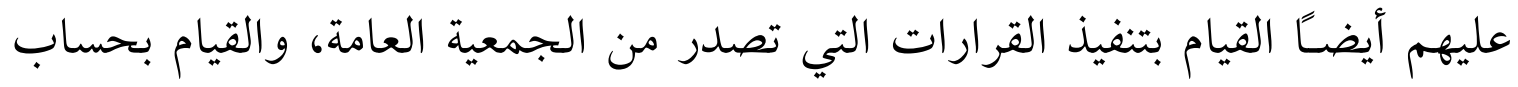

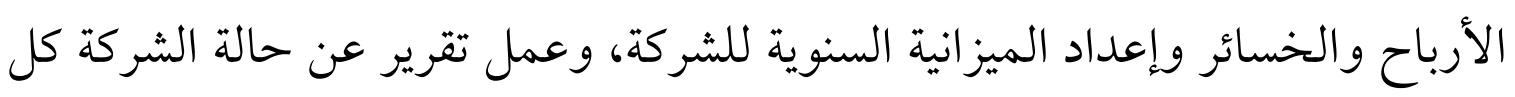
عام وتقديمة للجمعية العامة (1). وبعمل أعضاء مجلس الإدارة يعتبرون ممثلين عن الشركة، وأيضًا وكلاء عنها،

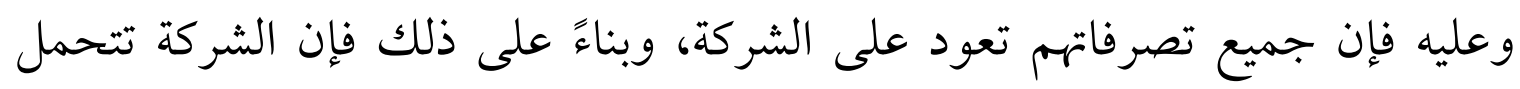

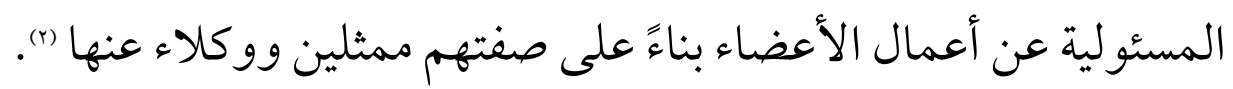

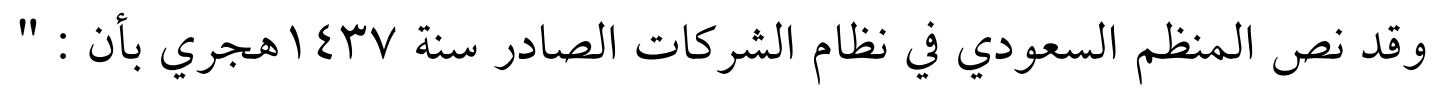
تلتزم الشركة بجميع الأعمال والتصرفات التي يجريها مجلس الإدارة ولو كانت خارج

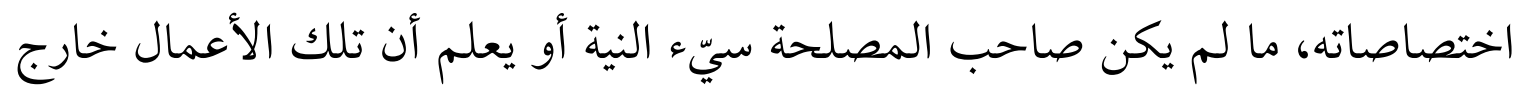
اختصاصات المجلس" (r) .

(1) صالح بن زبن المرزوقي البقمي، شركة المساهمة في النظام السعودي، دراسة مقارنة بالفقه الإسلامي، جامعة

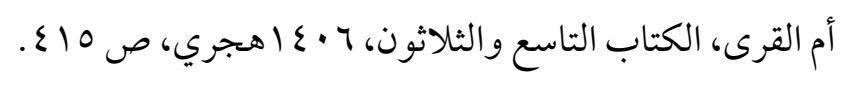

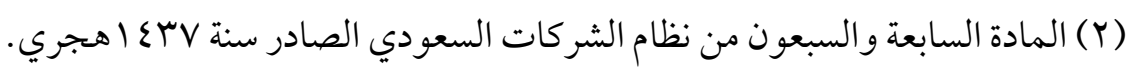

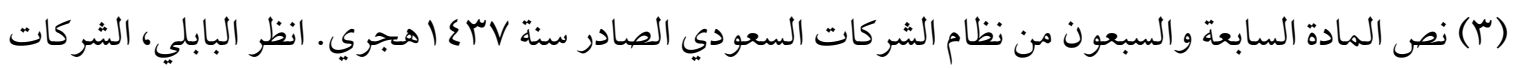

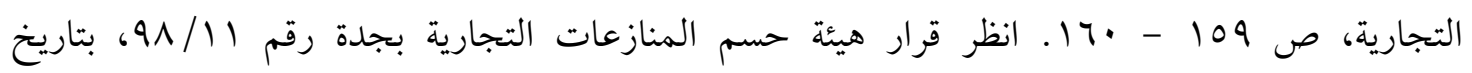

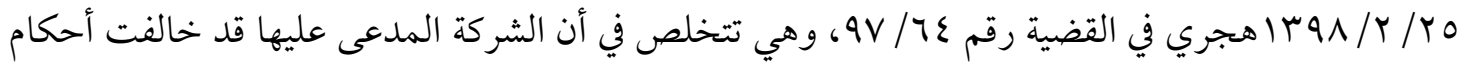
المادة r ا من نظام الشركات القديم بخلو مطبوعاتها من إيضاح الاسم النظامي للشركة، وقد دافعت الشركة المدعى عليها بأن الموظف الذي أصدر الخطاب سهى عن وضع الختم عليه لتكتمل البيانات المطلوبة نظامكا،

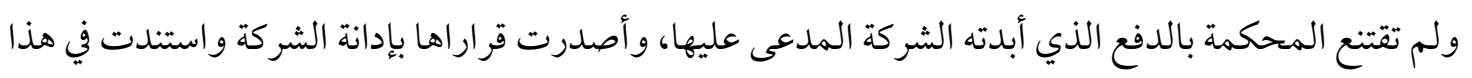
القرار بأن الموظف تابع للشركة، والشركة مسؤولة عن أعمال تابعها. 
وعليه فلا مسؤولية على أعضاء المجلس إذا قاموا بأعمالهم بعناية وضمن الأصول

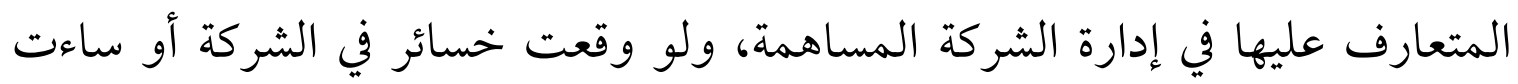

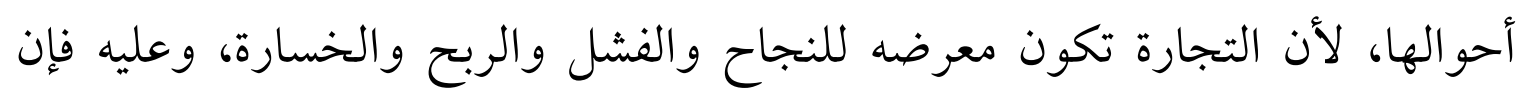
الشركة تتحمل في مثل هذه الحالة جميع تصرفات أعضاء المجلس. المطلب الثاني

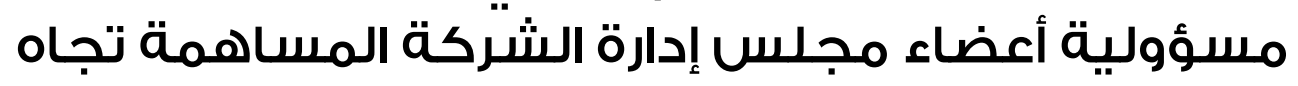
المساهمين في نظامج الشركات السعارة السعودي المساهي

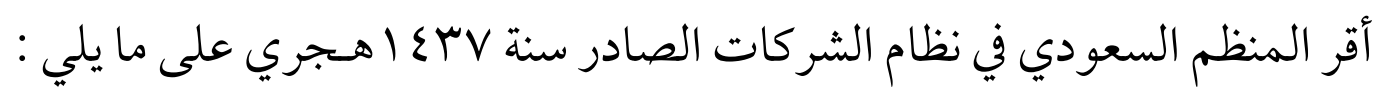
1 - يكون أعضاء مجلس الإدارة مسؤولين - بالتضامن - عن تعويض الشركة

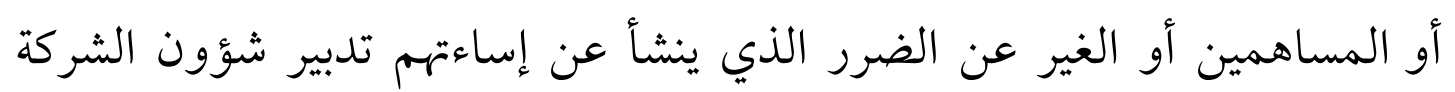

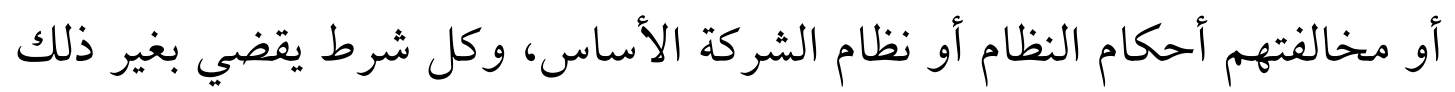
يعد كأن لم يكن. وتقع المسؤولية على جميع أعضاء مجلس الإدارة إذا نشأ الخطأ

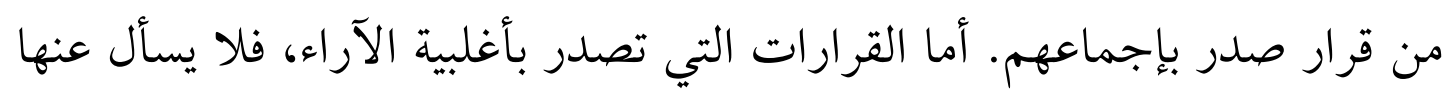

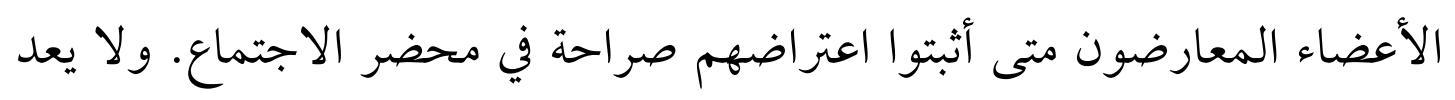

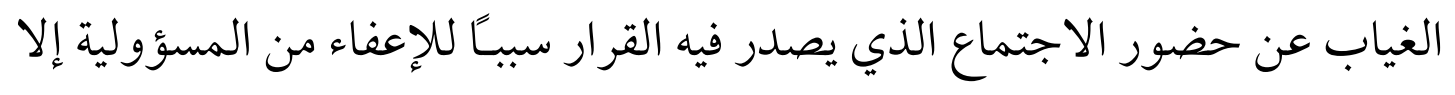

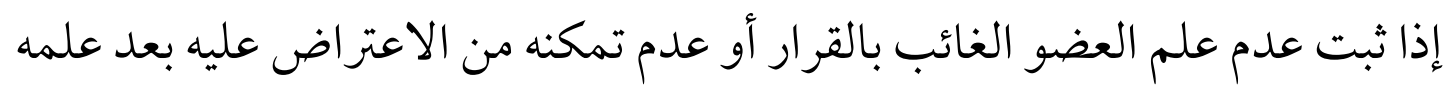
ب. ץ- لا تحول دون إقامة دعوى المسؤولية موافقة الجمعية العامة العادية على إبراء ذمة أعضاء مجلس الإدارة.

r- لا تسمع دعوى المسؤولية بعد انقضاء ثلاث سنوات من تاريخ اكتشاف الفعل

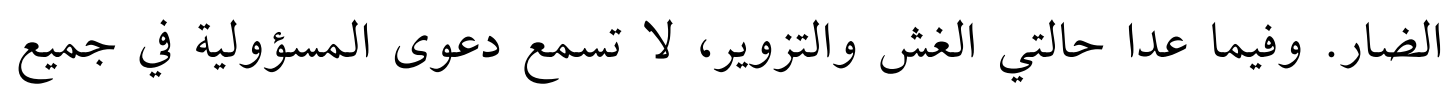


الأحوال بعد مرور خمس سنوات من تاريخ انتهاء السنة المالية التي وقع فيها الفعل الضار أو ثلاث سنوات من انتهاء عضوية عضو مجلس الإدارة المعني أيهما

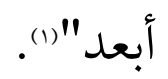

وهناك أمثلة عديدة للمخالفات التي قد تقع من مجلس إدارة الشركة المساهمة وذلك نتيجة عدم القيام بالواجبات التي تقع على عاتق المجلس ويكون المجلس مسؤول عن هذه المخالفات. ويعد من المخالفات القانونية التي يكون مجلس الإدارة مسؤول عنها هي ما نصت عليه المادة التاسعة والعشرون بعد المائة من نظام الشركات الصادر سنة I I V هجري من أن المجلس مسؤول عن عدم تكوين الاحتياطي النظامي

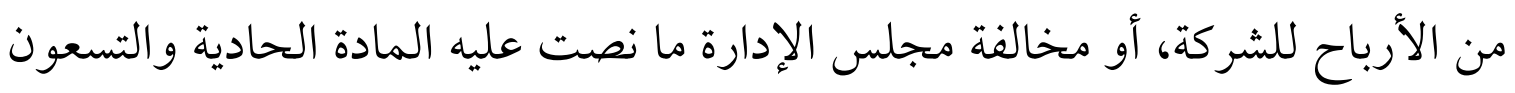
من نظام الشركات الصادر سنة VY I ا هجري من عدم تزويد المساهمين بالمعلومات اللازمة قبل انعقاد جلسات الجمعية العمومية، أو ما نصت عليه المادة السادسة والعشرون بعد المائة من نظام الشركات الصادر سنة I I I هجري على عدم قيام المجلس من إعداد القوائم المالية السنوية والتقرير السنوي للشركة، أو التصديق على حسابات غير صحيحة وتوزيع أنصبة أرباح صورية). يستطيع المتضرر أن يرفع دعوى الضرر على عضو مجلس الإدارة المسؤول الذي صدر منه الضرر ويكون ذلك خلال ثلاث سنوات من تاريخ اكتشاف الفعل الضار، ولا تسمع الدعوى بعد انتهاء الثلاث سنوات. وفيما عدا حالتي الغش والتزوير، لا تسمع دعوى المسؤولية بعد مرور خمس سنوات من تاريخ انتهاء السنة المالية التي وقع فيها

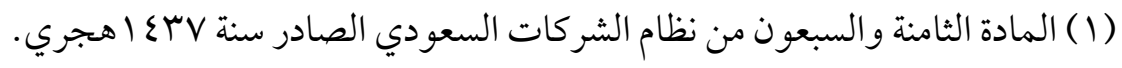

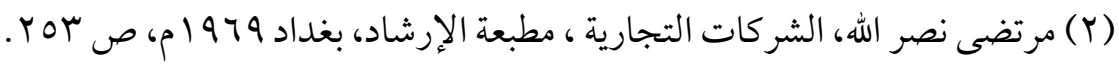


الفعل الضار أو ثلاث سنوات من انتهاء عضوية عضو مجلس الإدارة الذي صدر منه الفعل الضار. ويكون مديرو الشركة المساهمة مسئولين أمام كل متضرر عما يصدر منهم من أعمال مخالفة كما نصت عليه المادة الحادية عشرة بعد المائة من نظام الشركات السعودي الصادر سنة IR أ هجري وهي كتالي: كل مدير سجَّل بيانات كاذبة أو مضللة في القوائم المالية أو فيما يعده من تقارير للشركاء أو للجمعية العامة، أو أغفل تضمين هذه القوائم أو التقارير وقائع جوهرية بقصد إخفاء المركز المالي للشركة عن الشركاء أو غيرهم. كل مدير يستعمل أموال الشركة أو يستعمل السلطات التي يتمتع بها أو الأصوات التي يحوزها بتلك الصفة استعمالاً يعلم أنه ضد مصالح الشركة لتحقيق أغراض شخصية أو لمحاباة شركة أو شخص أو الانتفاع من مشروع أو صفقة له فيها مصلحة مباشرة أو غير مباشرة. كل مدير لم يدعُ الجمعية العامة للشركة أو الشركاء أو لم يتخذ ما يلزم لذلك بحسب الأحو ال عند علمه ببلوغ الخسائر الحدود المقدرة للشركة أو لم يشهر الواقعة"). وكذلك كل مخالفة صادرة من مدير الشركة المساهمة كما نصت المادة الثانية عشرة من نظام الشركات السعودي الصادر سنة VI乏 ا هجري على أن كل من يُثبت عمداً في عقد تأسيس الشركة أو في نظامها الأساس أو في غير ذلك من وثائق الشركة أو في طلب الترخيص بتأسيس الشركة أو في المستندات المرافقة لطلب التأسيس؛ بيانات كاذبة أو مخالفة لأحكام النظام، وكل من وقع تلك الوثائق أو نشرها مع علمه بذلك. كل من بالغ أو قدم إقرارات كاذبة من الشركاء أو من غيرهم فيما يخص تقويم الحصص

(1) راجع المادة الحادية عشرة بعد المائة من نظام الشركات السعودي الصادر سنة VrV ا هجري. 
العينية أو توزيع الحصص بين الشركاء أو الوفاء بكامل قيمتها مع علمه بذلك، سواء كان

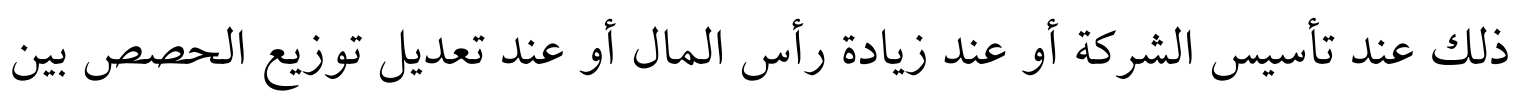

\section{المطلب الثالث الثمار}

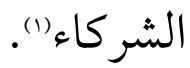

\section{مسؤولية أعضاء مجلس إدارة الشركة المساهمة تجاه الغير في ظل نظامم الشركات السعودي}

نصت الفقرة الأولى من المادة الثامنة والسبعون من نظام الشركات السعودي الصادر سنة I I I هجري. على أن أعضاء مجلس الإدارة مسؤولين بالتضامن عن تعويض الشركاء أو المساهمين أو الغير عن الضرر الذي ينشأ عن إساءتهم تدبير شؤون الشركة النظام أو نظام الشركة الأساس، وكل شرط يقضي بغير ذلك يعد كأن لم يكن (). والجدير بالذكر أن هناك تفاوت بين نصوص القانون المقارن في هذا الشأن فقد ذهب بعضها إلى ما ذهب إليه نظام الشركات السعودي الصادر سنة VY إهجري، ولكن كانت عبارات النص أكثر وضوحكا من عبارات نص المادة الثامنة والسبعون من نظام الشركات السعودي الصادر سنة Vץ؟ اهجري ومنها على سبيل المثال ما نصت عليه بعض المواد في نظام الشركات العربية : على أن رئيس وأعضاء مجلس الإدارة مسؤولون تجاه الغير (....) عن الخطأ في الإدارة(")، وأن أعضاء مجلس الإدارة مسؤولون تجاه الغير عن(.....) أو إهمال يرتكبونه في أداء مهامهم، وكذلك عدم

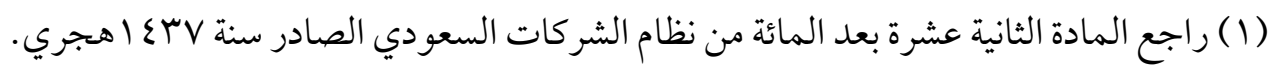

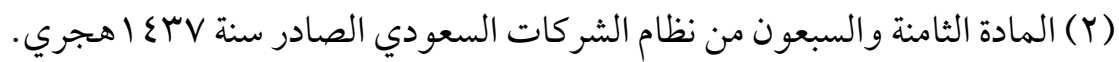

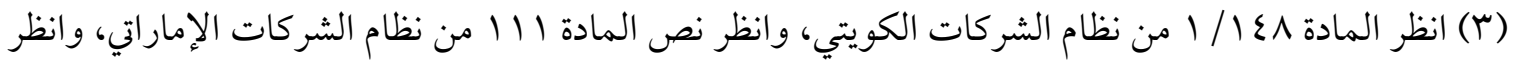

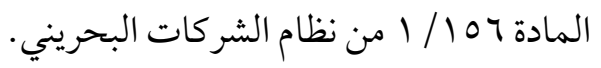




\section{تصرف الشخص المتبصر في ظروف معينة").}

ويتضح لنا من هذه النصوص أن هناك مسؤولية نتيجة عن أخطاء رئيس وأعضاء مجلس الإدارة الإدارية تجاه الشركة والمساهمين والغير وهذا ما نص عليه النظام السعودي و الأنظمة المقارنة. ولكن من يدعي الخطأ الإداري الصادر من المسؤولين أن يثبت هذا الخطأ بكافة طرق الإثبات المتاحة. وهذا تأكيداً على أن أعضاء المجلس مسؤولين عن كل خطأ في سوء الإدارة يسبب ضرراً للغير، ولو لم يكن الخطأ نتيجة غش أو مخالفة أنظمة الدولة أو النظام الأساسي للشركة المساهمة()، ويجب أن يكون الخطأ كنتيجة لإخحلال المسؤول عن العناية المعتادة في جميع الأعمال والتصرفات التي تختص في إدارة الشركة(r)، ومثال ذلك عدم اعتناء المجلس بالمسائل المعروضة عليه بصورة كافية، أو إهماله بالقيام بو اجباته، أو سوء تنظيم أعمال الشركة، أو سوء لإدارة في عملية الإنتاج وتصريف الخدمات، أو سوء معاملة موظفين وعمال الشركة، أو القيام بعمليات فيها مخاطرة التي تؤثر في المركز المالي للشركة، مثل توزيع أرباح صورية على المساهمين()، أو التهاون وعدم الاهتمام في تحصيل ديون الشركة لدى الغير أو عدم اتخاذ الإجراءات الاحتياطية للمحافظة على حقوق الشركة(0).

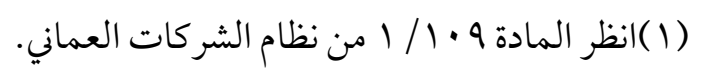

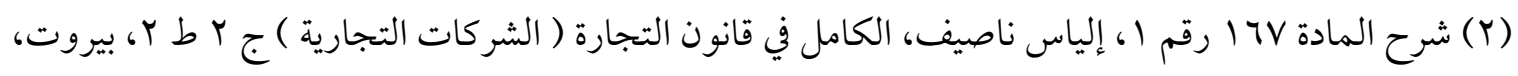

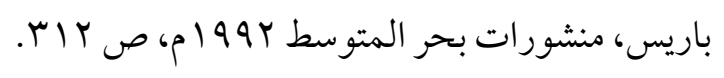

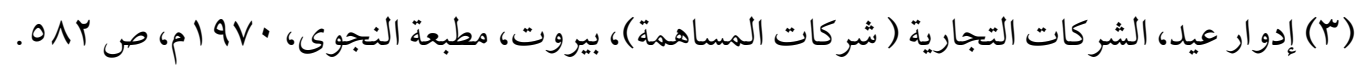
(ع) على حسن يونس، الشركات التجارية ( الشركات ذات المسؤولية المحدودة ، وشركات المساهمة والتوصية

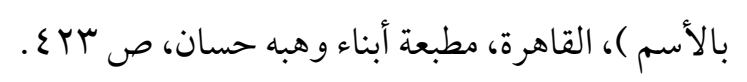

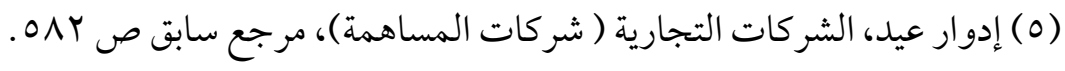




\section{المبحث الثاني}

\section{الرقابة الداخلية والخارجية على أعمال شركات المساهمة}

نصت المادة الثانية والثلاثون بعد المائة من نظام الشركات الصادر سنة I V

هجري. على الأصل في الرقابة على الشركة يكون عن طريق جمعية المساهمين وهي رقابة داخلية على أعمال الشركة، ولكن هناك أيضًا رقابة خارجية على أعمال شركة المساهمة وسوف نقسم هذ المبحث إلى مطلبين: المطلب الأول: أعمال الرقابة الداخلية. المطلب الثاني: أعمال الرقابة الخارجية.

\section{المطلب الأول أعمال الرقابة الداخلية}

للمحافظة على حقوق المساهمين والغير وعدم التفريط في حقوقهم، وحث مجلس الإدارة على الأداء والعمل لتحقيق غرض الشركة حرص نظام الشركات الصادر سنة VY I ا هجري على إتاحة رقابة داخلية على أعمال وإدارة شركة المساهمة وذلك من خلال رقابة مساهمين الشركة، ولجنة المراجعة، ومر اجعة الحسابات"(1).

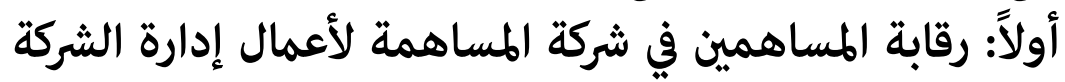
يعتبر فقهاء القانون أن الأصل في الرقابة على أعمال مجلس إدارة الشركة المساهمة يكون للمساهمين لشركة المساهمة، ويكون لهم أيضًا الإشراف و مراجعة الحسابات وجميع دفاتر الشركة ولذلك للتأكد من حسن إدارة مجلس إدارة الشركة لأعمالها()..

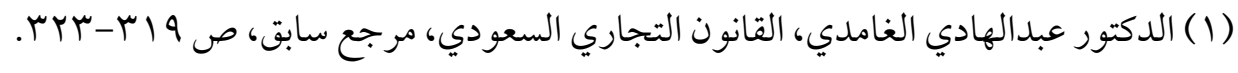
(r) سعيد يحيى، الوجيز في النظام التجاري السعودي، الطبعة الثانية، مطبعة المكتب العربي الحديث للطباعة 
ونجد في أن المنظم السعود قد أكد على هذا الحق في نظام الشركات الصادرة سنة I \& هV المساهمون الرقابة على حسابات الشركة وفقـا للأحكام المنصوص عليها في النظام

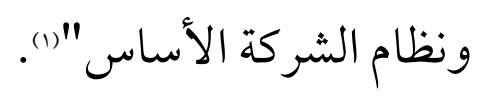

ولقد أضاف المنظم السعودي لهذا الحق حقوق أخرى للمساهمين ومنها حق طلب دفاتر الشركة والاطلاع عليها وعلى وثائق الشركة ومراقبة أعمال مجلس الإدارة. نصت المادة العاشرة بعد المائة من نظام الشركات الصادرة سنة Vr ا ا هجري على أن للمساهمين ( ( .) حق حضور جمعيات المساهمين، والاشتراك في مداولاتها، والتصويت على قراراتها، وحق التصرف في الأسهم، وحق طلب الاطلاع على دفاتر الشركة ووثائقها، ومراقبة أعمال مجلس الإدارة، ورفع دعوى المسؤولية على أعضاء المجلس، والطعن بالبطلان في قرار جمعيات المساهمين، وذلك بالشروط والقيود الواردة في النظام أو في نظام الشركة الأساس"(r). ولم يقتصر المنظم السعودي على هذ الحقوق فقط ولكن أعطى للمساهمين الذي تزيد نسبة حصتهم في الشركة المساهمة على ٪\% أن يلجئوا إلى الجهات القضائية المختصة للقيام بالتفتيش على الشركة إذا أتضح لهم أو ما يدعو إلى الريبة من قيام أعضاء مجلس الإدارة أو مراجع الحسابات القيام بأعمال قد تخالف النظام العام

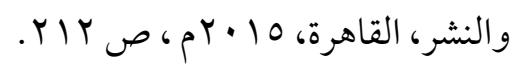

(1) المادة الثانية والثلاثون بعد المائة من نظام الشركات السعودي الصادر سنة لمr إهجري.

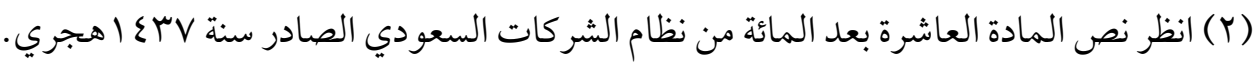


أو النظام الأساسي للشركة وهذا ما نصت عليه المادة المائة من نظام الشركات الصادرة سنة I I V هجري بأن " للمساهمين الذين يمثلون (0\%) على الأقل من رأس المال أن يطلبوا من الجهة القضائية المختصة الأمر بالتفتيش على الشركة إذا تبين لهم من تصرفات أعضاء مجلس الإدارة أو مراجع الحسابات في شؤون الشركة ما يدعو إلى

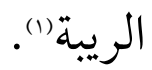

وذكرت المادة الخامسة من لائحة حو كمة الشركات الصادرة عن مجلس هيئة السوق المالية بأن للمساهمين "(...) "الاستفسار وطلب الاطلاع على دفاتر الشركة ووثائقها، ويشمل ذلك البيانات والمعلومات الخاصة بنشاط الشركة واستراتيجيتها التشغيلية والاستمارية بما لا يضر بمصالح الشركة ولا يتعارض مع نظام الشركات ونظام السوق المالية ولوائحهما التنفيذية. مراقبة أداء الشركة وأعمال مجلس الإدارة. مساءلة أعضاء مجلس الإدارة ورفح دعوى المسؤولية في مواجهتهم، والطعن ببطلان قرارات جمعيات المساهمين العامة والخاصة وفق الشروط والقيود الواردة في نظام الشركات ونظام الشركة الأساس.(r) بناءً على ما سبق فإن للمساهمين في شركة المساهمة الرقابة والإشراف ومراجعة الحسابات والاطلاع على جميع دفاتر شركة المساهمة ولذلك للتأكد على حسن إدارة

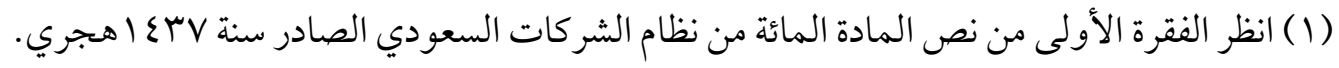

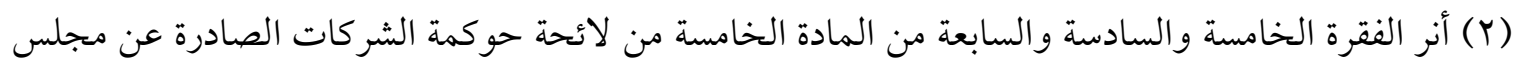

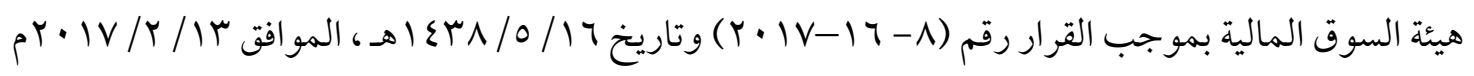

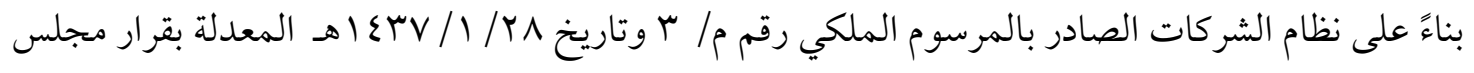

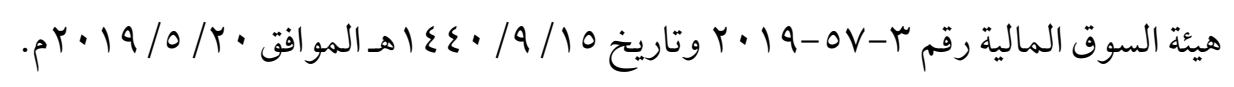




\section{مجلس إدارة الشركة لأعمالها وإدارتها للشركة.}

ولكن هناك أسباب أدت إلى عدم فعالية هذه الرقابة ومن ضمن هذه الأسباب العدد

الهائل من المساهمين في الشركات المساهمة، و مراجعة دفاتر الشركات وحساباتها

تحتاج إلى خبرات فنية معينة قد لا تتوفر في المساهمين، وعمليات الشركة المساهمة قد تتطلب المحافظة على ولكن المساهمين غير مستقرين في المشاركة في الشركات المساهمة وقد يتغيرون ويتبدلون عن طريق تداول الأسهم وعليه من الممكن أن ينشر المساهم بأسرار الشركة بعد بيعه لأسهمه في الشركة ولذلك فإن الكشف عن عمليات الشركة قد يضر بها وبسمعتها وقد ويؤدي في النهاية إلى انهيارها'). لذلك من الممكن أن تكون مراجعة الحسابات من خبراء معينين من الجمعية العامة للشركة المساهمة وهذا ما سنطرق إليه لاحقـًا. وعليه فإنه ليس من السهل على كل مساهم أن يتولى بنفسه الإشر اف على حسابات الشركة ، وأوضاعها المالية وميزانيتها ومدفوعاتها ، ونسب الأرباح ، وقد لايكون ذلك من اختصاصه ، لأنه يحتاج إلى خبرة فنية قد لا تتوفر في كثير من المساهمين ، ورقابة المساهمين متعذرة عملا ، لأن عدد المساهمين كبير ، ويخشى لو أذن لكل منهم مباشرتها أن تتعطل أعمال المديرين، وقد يسيء المساهمون استعمال هذا الحق ، ويقع النزاع بين المديرين على أتفه الأمور ، فيختل سير العمل (()، لكل هذا أصبحت المصلحة العامة للشركة تقتضي وجود من يشرف على هذه الأعمال ويتحمل مسؤولية ذلك من

$$
\text { (1) (1) محمود سمير الشرقاوي ، مرجع سابق، ص IV0. }
$$

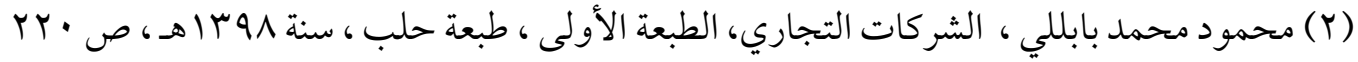


غير المؤسسين أو أعضاء مجلس الإدارة . وإذا ما نظرنا إلى داخل شركة المساهمة نفسها، نجد أن غالبية المساهمين يملك الو احد منهم قدر اضئيلا من الأسهم، ومن ثم فهو لا يعنى عادة بالرقابة والإشر اف على نشاط مجلس الإدارة، فوق عدم درايته بأنظمة الشركة ونشاطها، كل هذا يغري أعضاء مجلس الإدارة على العبث بحقوق المساهمين والاهتمام بمصالحهم الشخصية"). لكل ذلك قام المشرع في الكثير من الدول، بتنظيم هذا النوع من الشركات بقواعد آمرة، رعاية للمصالح المتعارضة فيها، حيث عمل على تمكين الجمعية العمومية للمساهمين من مباشرة رقابتها على مجلس الإدارة، وتشدد في مسئوليتهم، ثم نظم عملية التفتيش على الشركات (r) . غير أن المشرع إذا كان قد عمل على تدرج الهيئات التي تتولى إدارة شركة المساهمة، وتقسيم السلطات فيما بينها بهدف تحقيق التوازن بين هذه الهيئات، بحيث يكون لكل منها سلطتها ومهامها الخاصة، ونطاق عملها المحظور على الهيئات الأخرى أن تعتدي عليه، فلا يجوز لهيئة أن تحل محل أخرى، ما دام أن ذلك يمثل خرقا لنص صريح في القانون أو في نظام الشركة. فهو أيضا قد عمل على وجود هذا الفصل والتدرج، بين مجلس الإدارة والأشخاص الذين يساعدونه في القيام بمهامه، كرئيس مجلس الإدارة والعضو المنتدب والمديرين، ويجد هذا التدرج صداه في سلطة تعيين وعزل هؤ لاء والتي يملكها مجلس الإدارة نفسه (r).

(1) د/ حمدي محمود بارو د، أحكام القانون التجاري الفلسطيني، الشركات التجارية، الجزء الثالث، الطبعة

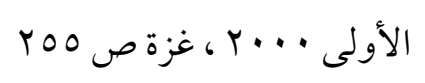

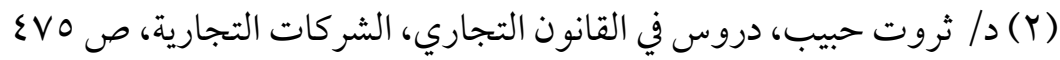
(r) د/ صلاح أمين أبو طالب، تجاوز السلطة في مجلس إدارة شركة المساهمة، دراسة مقارنة في القانون المصري 


\section{ثانياً : مراجعة الحسابات}

يعتبر مرجع الحسابات المرحلة المهمة في الرقابة الداخلية للشركة المساهمة، لأن مراجعة الحسابات تتم عن طريق خبراء محاسبين ممارسين لعملة الرقابة المالية في الشركات المساهمة ويتم اختيارهم بعناية من قبل الجمعية العامة العادية لشركة

(1) المساهمة

مراجع الحسابات والشخص المصرح له العمل بالمملكة العربية السعودية والذي يتمتع باستقلاليه والكفاءة والخبرة والذي تتعاقد معه لشركة للقيام بأعمال الرقابة الداخلية للشركة من عمل فحص ومراجعة القوائم المالية للشركة ومن حسابات الأرباح والخسائر والرقابة على أعمال مجلس إدارة الشركة لتأكد من تطبيقها لنظام الشركات السعودي ونظام الشركة الأساسي، وبين نظام الشركات مسؤوليات واختصاص والشروط الواجب توفرها في مراجع الحسابات(r)، وعليه سوف نعرض الشروط الواجب توفرها في مراجع الحسابات واختصاصاته ومسؤولياته، الشروط الواجب توفرها في مراجع الحسابات، كالآتي: حدد نظام الشركات شروط واجب توفرها في مراجع الحسابات لتحقيق النزاهة و الكفاءة المهنية و الحيدة في عمله، وتخلف هذه الشروط يصبح عمله مراجع الحسابات باطلاً، و وعليه يشترط في مراجع الحسابات: 1 - يجب أن يكون للشركة مراجع حسابات (أو أكثر) من بين مراجعي الحسابات

$$
\text { و الفرنسي، ط } 1999 \text { ، دار النهضة العربية، ص ץ . }
$$

(1) المادة الثالثة والثلاثون بعد المائة من نظام الشركات السعودي الصادر سنة كrV أهجري.

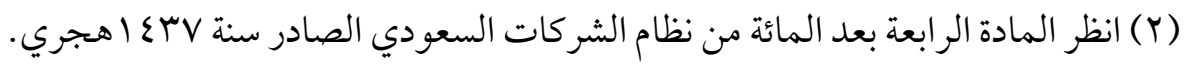


المرخص لهم بالعمل في المملكة تعينه الجمعية العامة العادية، وتحدد مكافأته

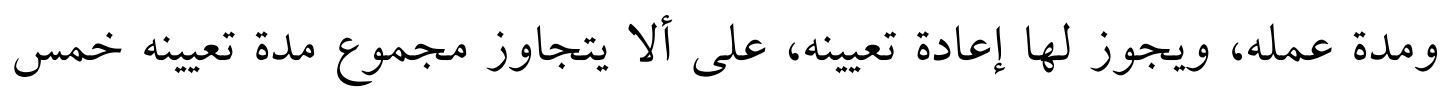

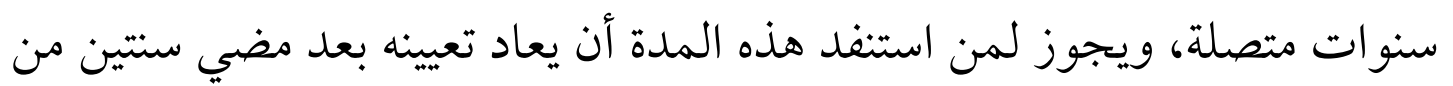
تاريخ انتهائها. ويجوز للجمعية أيضًا في كل وقت تغييره مع عدم الإخلال بحقه في التعويض إذا وقع التغيير في وقت غير مناسب أو لسبب غير مشروع. r- لا يجوز الجمع بين عمل مراجع الحسابات والاشتراك في تأسيس الشركة أو عضوية مجلس الإدارة أو القيام بعمل فني أو إداري في الشركة أو لمصلحتها ولو

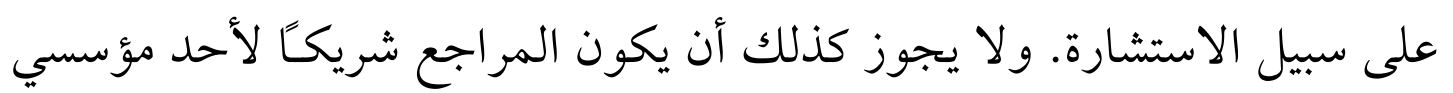

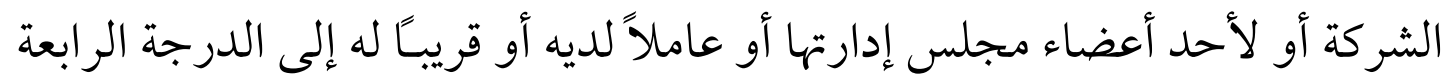

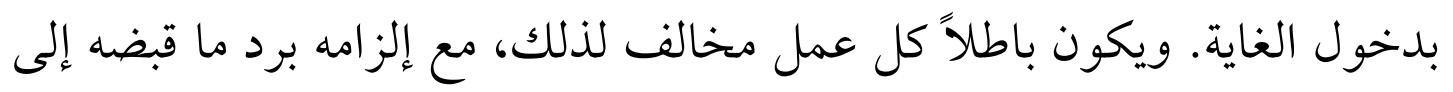

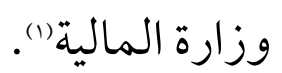

وعليه فإذا تحققت الشروط السابقة فإن عمل مراجع الحسابات يكون صحيحًا، وذلك من أن يكون ممن يكون مرخص لهم القيام بأعمال مراجعة الحسابات و من ثم يتم تعيينهم من قبل الجمعية العامة العادية للشرك المساهمة، وألا يكون للمراجع أي علاقة أو مصلحة في الشركة المساهمة وأحسن المنظم في ذلك لكي لا يكون هناك تجاوزات من قبل المراجع للحصول على مصلحة مادية أو معنوية تؤدي إلى الإخلال بنز اهته واستقلاليته (1).

(1) المادة الثالثة والثلاثون بعد المائة من نظام الشركات السعودي الصادر سنة V V أ هجري. (Y) د. صالح البقمي، شركة المساهمة في النظام السعودي دراسة مقارنة بالفقه الإسلامي: منشورات جامعة أم 


\section{- اختصاصات مراجع الحسابات:}

يعد عمل مراجع الحسابات هو مراجعو ومراقبة حسابات الشركة، فيحق لمراجع

الحسابات في أيّ وقت حق الاطلاع على دفاتر الشركة وسجلاتها وغير ذلك من الوثائق، وله أن يطلب البيانات والإيضاحات التي يجب أن يحصل عليها وتكون ضرورية لتحقيق عمله، وله التحقق من موجودات الشركة والتزاماتها وغير ذلك مما يدخل في نطاق عمله. ولذلك من الواجب على رئيس مجلس الإدارة أن يمكنه من أداء واجبه، وإذا حدث أي معوقات تعيق عمل مراجع الحسابات أثثت ذلك في تقرير يقدم إلى مجلس الإدارة. فإذا لم يقدم مجلس الإدارة ما يسهل عمل مراجع الحسابات ، وجب عليه أن يطلب من مجلس الإدارة دعوة الجمعية العامة العادية للنظر في الأمر (1). وعلى مراجع الحسابات أن يقدم إلى الجمعية العامة العادية السنوية تقريراً، وفقًا لمعايير المراجعة المتعارف عليها، يضمنه موقف إدارة الشركة من تمكينه من الحصول على البيانات والإيضاحات التي طلبها، وما يكون قد تبين له من مخالفات لأحكام النظام أو أحكام نظام الشركة الأساس، ورأيه في مدى عدالة القوائم المالية للشركة. ويتلو مراجع الحسابات تقريره في الجمعية العامة. وإذا قررت الجمعية التصديق على تقرير مجلس الإدارة والقوائم المالية دون الاستماع إلى تقرير مراجع الحسابات، كان قرارها باطلاً

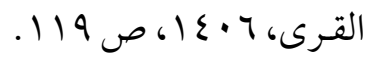

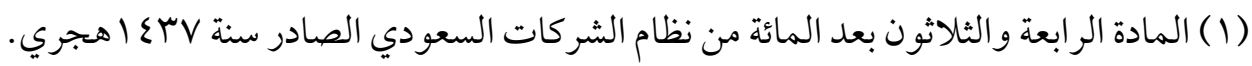

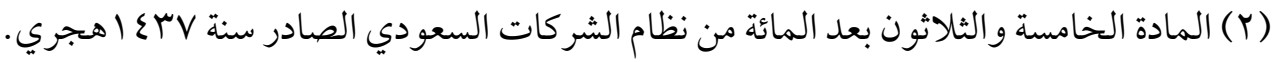


وعليه يتضح مما سبق أن الجمعية العامة للشركة المساهمة تتكون من المساهمين لذلك تعتبر الممثل الرسمي المساهمين في شركة المساهمة وتصدر قرار تعيين مراقب الحسابات بأغلبية الأصوات في الجمعية العامة ولذلك تعتبر السلطة العليا تعيين مراقب

$$
\text { - الحسابات في الشركات المساهمة") }
$$

لا يحق لمراجع الحسابات أن يفشي ما وقف عليه من أسرار الشركة بسبب قيامه بعمله، إلى المساهمين في غير الجمعية العامة أو إلى الغير، وإلا وجب عزله ومطالبته بالتعويض. ويسأل مراجع الحسابات عن الأخطاء التي تقع منه في أداء عمله. و إذا تعدد المراجعون واشتركوا في الخطأ كانوا مسؤولين بالتضامن عن تعويض الضرر الذي يصيب الشركة أو المساهمين أو الغير بسبب الخطأ و الضرر الذي وقع (r). وتقوم المسؤولية الجنائية على مراجع الحسابات إذا اقترف جريمة من الجرائم المعاقب عليها قانونيـا وتعد جريمة مثل النصب والتزوير وخيانة الأمانة، وعليه فيعاقب كل مراجع حسابات قام بتسجيل بيانات كاذبة أو مظللة في القوائم المالية أو التقرير الذي يعده، أو قام بإخفاء المركز المالي للشركة عن الشركاء أو الغير بعدم تضمين القوائم الملية أو التقارير وقائع جوهرية أولم يقم بدعوة الجمعية العامة أو اتخاذ ما يلزم عند علمه ببلوغ الخسائر المحددة نظامًا، إن العقوبة المقدرة لهذه الأعمال هي السجن لمدة لا تزيد عن خمس سنوات وبغرامة لا تزيد على خمسة ملايين ريال أو بإحدى 
هاتين العقوبتين.

ويعاقب بالسجن مدة لا تزيد عن سنة وبغر امة لا تزيد على مليون ريال، أو بإحدى

هاتين العقوبتين، عند عدم قيام مراجع الحسابات بتبليغ الشركة عن المخالفات التي أكتشفها أثناء عمله والتي يشتمل على مخالفة جنائية أوفي حالة المبالغة أو تقديم إقرارات كاذبة عن الوفاء بكامل حصص الشركة.

ويعاقب مراجع الحسابات بغرامة مالية فقط لا تزيد على خمسمائة ألف ريال في حالة علم مر اجع الحسابات أو توزيعه أو عوائد مخالة لأحكام نظام الشركات أو نظام الشركة الأساسي، أو قيامه بالاستمر ار بعمله مع العلم بأن هناك ما يمنع قيامه بعمله، أو أن يعيق عمل من لهم حق الاطلاع على أوراق الشركة ومستنداتها وحسابتها ووثائقها أو أن يكوون سبب في ذلك أو أن يكون سبب ي هذه إعاقة من لهم حق في ذلك، وفي جميع الأحوال يجوز للجمعية العامة عزل مراجع الحسابات ودون الإخلال بحقة في التعويض عن العزل بدون مبرر أو بدون عذر، ويكون مراجع الحسابات عرضه للجزاء التأديبية عند إخلاله بقواعد مهنته، من لوم وإنذار وتوقيف عن العمل أو يشطب أسمه نهائيًا من قوائم المحاسبيين (1) ثالثاً: لجنة المراجعة

إن من المهام التي الزم بها نظام الشركات السعودي على مجلس إدارة الشركة المساهمة القيام بإحداث نظام رقابي داخلي في الشركة. فرض نظام الشركات على شركة المساهمة تكوين لجنة مراجعة من المساهمين أو من غيرهم لتحقيق الرقابة

(1) ينظر المادة (Yq) من نظام المحاسبيين القانونيين الصادر المرسوم الملكي رقم(م/r/ (I) وتاريخ

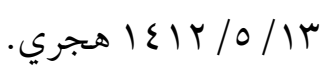


الداخلية على إدارة وأعمال شركة المساهمة، لتحقق من كفاءة الشركة وتقديم التوصيات المهمة والضرورية لمجلس إدارة الشركة للقيام بأعمال تهدف إلى تطوير الشركة والوصول إلى تحقيق أهدافها. لذلك صدر القرار الوزاري رقم (YYIV) في

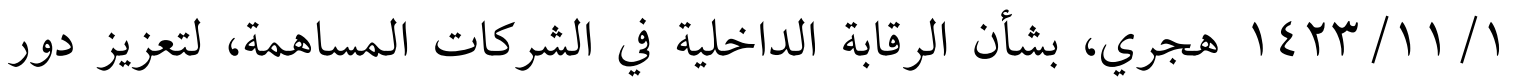
الرقابة الداخلية في الشركات المساهمة والاهتمام") بدور لجنة المراجعة في تطوير أعمال الشركة المساهمة.

وهذه اللجنة لا يدخل في تكوينها أي عضو من أعضاء مجلس الإدارة. وتشكل وتحدد مهامها وضو ابط عملها ومكافئات أعضائها بقرار من الجمعية العادية. وتتمثل اللجنة من عدد لا يقل عن ثلاثة أعضاء ولا يزيد عن خمسة، وتكون اجتماعاتها صحيحة بحضور أغلبية الأعضاء، وتصدر القرارات بأغلبية أصوات الحضور، وبتساوي الأصوات يرجع الصوت الذي صوت معه رئيس الاجتماع()، ونرى أن يكون من بين أعضاء اللجنة مختص بالشؤون المالية والمحاسبية. اختصاص لجنة المراقبة هو المراقبة عل أعمال الشركة، والتحقق من صحة التقارير السنوية المعدة من قبل مجلس الإدارة، ولها التحقق من كفاية نظام الرقابة الداخلية للشركة والتأكد من فعاليته تنفيذه، ولها حق الاطلاع على سجلات الشركة وطلب الإيضاح وطلب بيان من أعضاء مجلس الإدارة أو الإدارة التنفيذية ويجوز لها تقديم

(1) سليمان الجهني، ضوابط الرقابة على شركة المساهمة، بحث ماجستير مقدم للجامعة الإسلامية بالمدينة

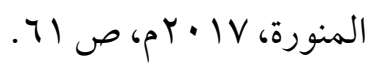

(Y) انظر المادة الأولى بعد المائة من نظام الشركات السعودي الصادر سنة VT؟ ا هجري. 


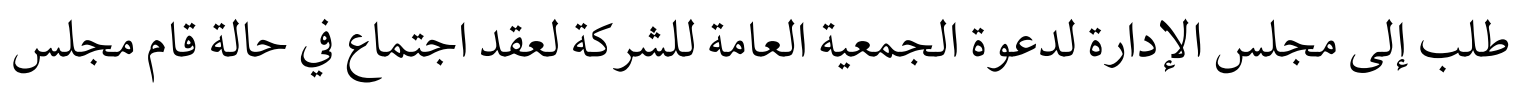
الإدارة بإعاقة عمل الشركة أو تعرضت الشركة لأضرار أو خسائر كبيرة'). ولها أيضًا التوصية لمجلس الإدارة بتعيين المحاسبيين القانوني للشركة والتوصية بتحديد اتعابهم ومتابعتهم وعزلهم جميع أعمالهم. ويمحور عمل اللجنة في الاطلاع على القوائم المالية للشركة والتقارير الصادرة من الشركة ومر اجعة الحسابات وبناءً عليه تعطي مرئياتها حيال ما تتطلع عليه و إبداء الرأي وعمل التوصيات المناسبة قبل العرض على مجلس الإدارة(). ولها أن تعطي رأيها حيال ما تراه في تقرر يبين مدى كفاية نظام الرقابة الداخلية في الشركة، وإعداد تقرير عما تقوم تهري به من أعمال يدخل في اختصاصها"(م). وللجنة أيضاً التأكد من تطبيق اللوائح المنظمة للشركة المساهمة، والسياسات

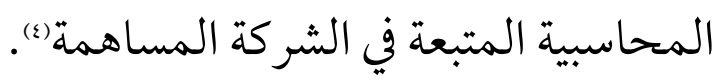
رابعاً: رقابة الجمعية العامة نصت المنظم السعودي في نظام الشركات على الدور المهم الذي تقوم به الجمعية العامة حيث نصت المادة السابعة والثمانون من نظام الشركات السعودي على أن "فيما عدا الأمور التي تختص بها الجمعية العامة غير العادية، تختص الجمعية العامة العادية

(1) انظر المادة الثالثة بعد المائة من نظام الشركات السعودي الصادر سنة (YrV ( هجري.

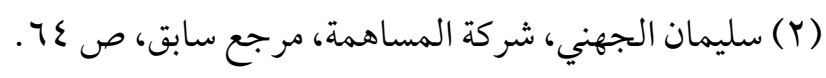

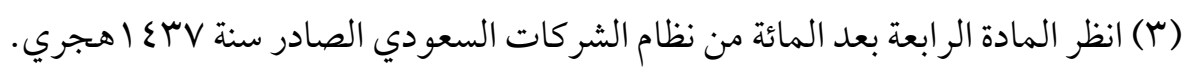
(ع) صالح عوض العقلا البلوي، الرقابة على أعضاء مجلس الإدارة في شركة المساهمة، مكتبة القانون والاقتصاد

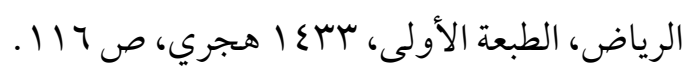


بجميع الأمور المتعلقة بالشركة، وتنعقد مرة على الأقل في السنة خلال الأشهر الستة التالية لانتهاء السنة المالية للشركة، ويجوز دعوة جمعيات عامة عادية أخرى كلما دعت

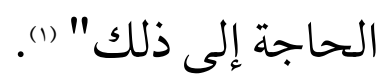

ونصت المادة الأولى بعد المائة من نظام الشركات السابق الذكر على أن "تشكل بقرار من الجمعية العامة العادية في شركات المساهمة لجنة مراجعة من غير أعضاء مجلس الإدارة التنفيذيين سواء من المساهمين أو من غيرهم، على ألا يقل عدد

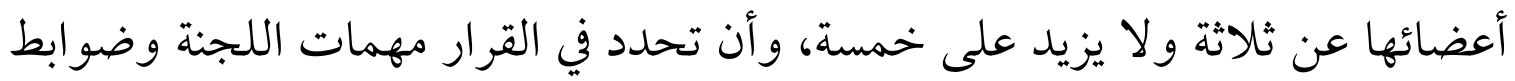

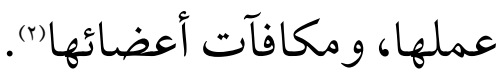

ونصت المادة الثالثة بعد المائة من نظام الشركات السابق الذكر على أن "تختص لجنة المراجعة بالمراقبة على أعمال الشركة، ولها في سبيل ذلك حق الاطلاع على سجلاتها ووثائقها وطلب أي إيضاح أو بيان من أعضاء مجلس الإدارة أو الإدارة التنفيذية، ويجوز لها أن تطلب من مجلس الإدارة دعوة الجمعية العامة للشركة للانعقاد إذا أعاق مجلس الإدارة عملها أو تعرضت الشركة لأضرار أو خسائر جسيمة" (r). ونصت المادة الرابعة بعد المائة من نظام الشركات السابق الذكر على أن "على لجنة المراجعة النظر في القوائم المالية للشركة والتقارير والملحوظات التي يقدمها مراجع الحسابات، وإبداء مرئياتها حيالها إن وجدت، وعليها كذلك إعداد تقرير عن رأيها في

(1) المادة السابعة والثمانون من نظام الشركات السعودي الصادر سنة V إع (هجري. (r) المادة الأولى بعد المائة من نظام الشركات السعودي الصادر سنة Vr₹ إهجري.

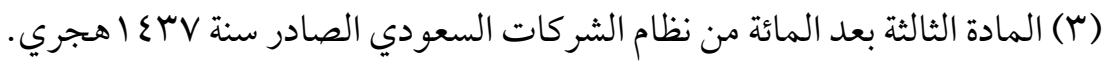


شان مدى كفاية نظام الرقابة الداخلية في الشركة وعما قامت به من أعمال أخرى تدخل في نطاق اختصاصها. وعلى مجلس الإدارة أن يودع نسخًا كافية من هذا التقرير في مركز الشركة الرئيس قبل موعد انعقاد الجمعية العامة بعشرة أيام على الأقل؛ لتزويد كل من رغب من المساهمين بنسخة منه. ويتلى التقرير أثناء انعقاد الجمعية" (1). وعليه فإن هذه النصوص تؤكد لنا الاختصاصات المؤكل إلى الجمعية العامة العادية وعليه فهي مختصة بأمور مهمة في شركة المساهمة ومنها تعيين أعضاء مجلس الإدارة ومراقبي الحسابات وإصدار السندات و إلغاء حصص التأسيس و رفع دعوى المسئولية على جميع أعضاء مجلس الإدارة نيابة عن الشركة. المطلب الثثاني أعمال الرقابة الخارجية

أقر نظام الشركات أن يكون هناك رقابة خارجية للشركة المساهمة من قبل جهة إدارية معينة بإضافة إلى التفتيش على اعمال الشركة المساهمة. أولاً : رقابة وزارة التجارة والاستثمار لوزارة التجارة والاستثمار بالنسبة للشركات المساهمة المغلقة، ولهيئة السوق المالية بالنسبة للشركات المساهمة المدرج أسمها في سوق الأسهم، حق الرقابة على الشركات لتأكيد تطبيق نظام الشركات ونظام الشركة الأساسي وجميع ما نص عليه في عقد الشركة المساهمة، كما يحق لهما التفتيش على الشركة وفحص الحسابات وطلب ما تراه

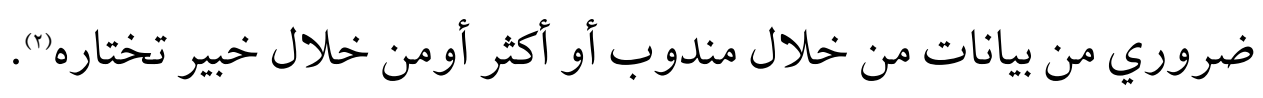

(1) (1) المادة الر ابعة بعد المائة من نظام الشر كات السعودي الصادر سنة VT \& اهجري.

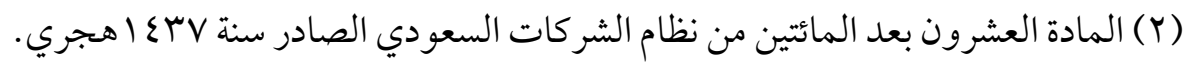


من غير الإخلال بعمل مؤسسة النقد السعودي بالتفتيش والرقابة على شركات

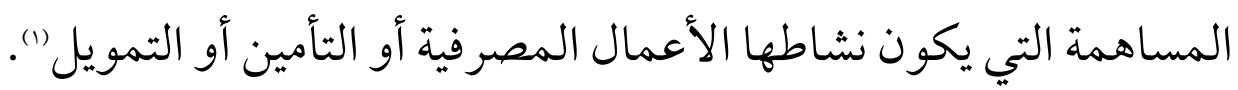

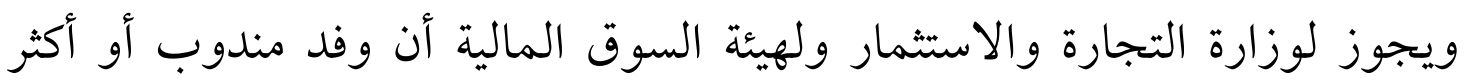
بو صفة مراقبًا لحضور الجمعية العامة للشركة للتأكد من تطبيق نظام الشركات(ب). ثانياً: رقابة الهيئة العامة لسوق الهال تقوم الهيئة العامة لسوق المال بالإشراف على السوق المالي، لذلك تقوم بتطوير السوق المالي، وإصدار التعليمات و القواعد المنظمة لسوق المال، وتقوم بالإشراف المباشر على التأكد من تطبيق نظام السوق المالية، وذلك لتأكد من توفر أجواء مناسبة للاستثمار في السوق، وزيادة الثقة في السوق من قبل المستثمرين، وحماية المستثمرين وجميع المتعاملين بالسوق من جميع الأعمال التي يتعلق بها شبهه وتكون غير

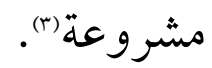
حيث تنص المادة الخامسة والأربعون من نظام السوق المالية على أنه: "أ- يجب على كل مصدر يطرح أوراقَّ مالية للجمهور أو تكون له أوراق مالية متداولة في السوق أن يقدم إلى الهيئة تقارير ربع سنوية وسنوية ، وتكون التقارير السنوية مدققة حسبما تنص عليه قو اعد الهيئة. على أن تتضمن هذه التقارير ما يأتي: الميزانية العمومية - حساب الأرباح والخسائر- قائمة الثدفق النقدي- أي سئي

(1) المادة التاسعة عشرة بعد المائتين من نظام الشركات السعودي الصادر سنة r اع ا هجري. (r) المادة الثالثة والستون من نظام الشر كات السعودي الصادر سنة لrV أهجري. (r) انظر مهام الهيئة العامة لسوق المال في نظام السوق المالية الصادر بموجب المرسوم الملكي رقم (م / • r)

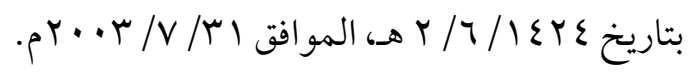




\section{معلومات أخرى تنص عليها قواعد الهيئة .}

ب- بالإضافة إلى المعلومات والبيانات المطلوبة في الفقرة (أ) من هذه المادة، يجب أن يتضمن التقرير السنوي ما يأتي :

ا - وصفًا كافيًا للشركة المصدرة وطبيعة عملها وأنشطتها، حسب ما تنص عليه القو اعد الصادرة عن الهيئة.

Y- معلومات تتعلق بأعضاء مجلس الإدارة والمديرين التنفيذيين وكبار الموظفين وكبار المساهمين أو المستثمرين، حسب ما تنص عليه القواعد الصادرة عن الهيئة. ب- تقويم إدارة الشركة المصدرة للتطورات الحالية والمتوقعة، وأي احتمالات مستقبلية يمكن أن تؤثر بصورة مهمة على نتائج أعمال الشركة أو وضعها المالي ، حسب ما تنص عليه القواعد الصادرة عن الهيئة. ع -أي معلومات أخرى تتطلبها قواعد الهيئة على النحو الذي تراه ضروريـًا لمساعدة المستثمرين ومستشاريهم على اتخاذ قرار الاستثمار في الأوراق المالية للمصدر.

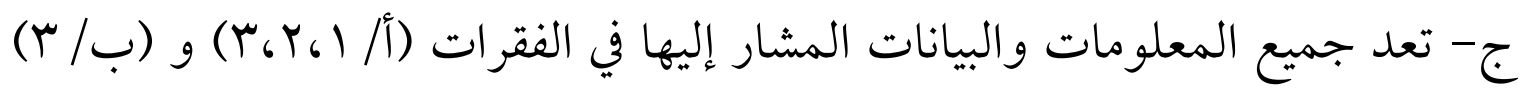
من هذه المادة معلومات سرية ـ ويحظر على الشركة المصدرة - قبل تزويد الهيئة بهذه المعلومات و البيانات وإعلانها - إفشاؤها إلى جهات لا يقع على عاتقها التزام بالمحافظة على سرية المعلومات وحمايتها" (1). وبناءً على النص السابق يمكننا القول أن هناك مدى واسع من الرقابة من الهيئة العامة لسوق المال على مجلس الإدارة في مجلس الإدارة شركات المساهمة. وعليه 
تقدم الشركات تقارير ربع سنوية وتتضمن هذه التقارير ما يلي:

ونصت المادة الثامنة من لائحة حوكمة الشركات الصادر عن هيئة السوق المالية، على الشركة أن تضع طرق الإفصاح وسياساته وإجراءاته و أنظمة الإشراف بصورة مكتوبة وفقًَ للنظام، وذلك وفقـَ لنص المادة الثامنة من لائحة حوكمة الشركات الصادرة عن مجلس هيئة السوق المالية بموجب القرار رقم ( 1 - I - V ا ب )

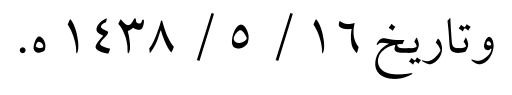

"على الشركة أن تضع سياسات الإفصاح وإجراءاته وأنظمته الإشرافية بشكل

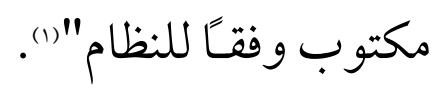
ونصت المادة التاسعة على الإفصاح في تقرير مجلس الإدارة حيث نصت على التالي:

"بالإضافة إلى ما ورد في قواعد التسجيل والإدراج بشأن محتويات تقرير مجلس الإدارة الذي يرفق بالقوائم المالية السنوية للشركة، يجب أن يحتوي تقرير مجلس

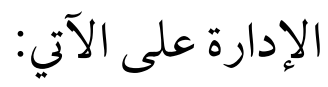

أ) ما تم تطبيقه من أحكام هذه اللائحة والأحكام التي لم تطبق وأسباب ذلك. ب) أسماء الشركات المساهمة التي يكون عضو مجلس إدارة الشركة عضواً في مجالس

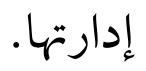
ج) تكوين مجلس الإدارة وتصنيف أعضائه على النحو الآتي: عضو مجلس إدارة

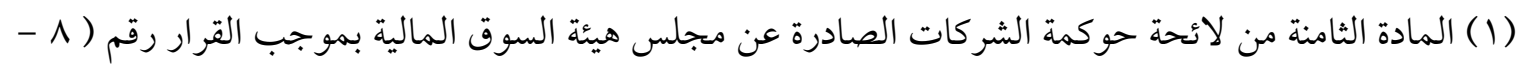

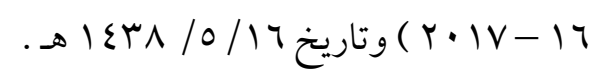


تنفيذي، أو عضو مجلس إدارة غير تنفيذي، أو عضو مجلس إدارة مستقل. د) وصف مختصر لاختصاصات لجان مجلس الإدارة الرئيسة ومهماتها مثل لجنة المراجعة، ولجنة الترشيحات والمكافآت، مع ذكر أسماء هذه اللجان ورؤسائها وأعضائها و عدد اجتماعاتها.

هـ) تفصيل عن المكافآت والتعويضات المدفوعة لكل من الآتي كل على حدة: ا ـ أعضاء مجلس الإدارة .

r . خمسة من كبار التنفيذيين من تلقو ا أعلى المكافأت و التعويضات من الشركة، يضاف إليهم الرئيس التنفيذي والمدير المالي إن لم يكونا من ضمنهم. و) أي عقوبة أو جزاء أو قيد احتياطي مفروض على الشركة من الهيئة أو من أي جهة إشر افية أو تنظيمية أو قضائية أخرى. ز) نتائج المراجعة السنوية لفاعلية إجراءات الرقابة الداخلية بالشركة"(1). ثالثًا: التفتيث:

إن التفتيش على الشركات المساهمة يمكن أن يكون بأمر من القضاء بناء على طلب من أحد الساهمين ونصت المادة المائة من نظام الشركات السعودي الصادر سنة VI إهجري على أن للمساهمين الذين يمثلون (0٪) على الأقل من رأس المال أن يطلبوا من الجهة القضائية المختصة الأمر بالتفتيش على الشركة إذا تبين لهم من تصرفات أعضاء مجلس الإدارة أو مراجع الحسابات في شؤون الشركة ما يدعو إلى

(1) المادة التاسعة من لائحة حو كمة الشركات الصادرة عن مجلس هيئة السوق المالية بموجب القرار رقم ( 1 -

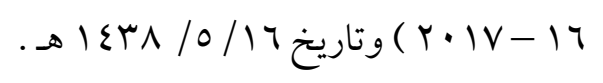


الريبة. وللجهة القضائية المختصة أن تأمر بإجراء التفتيش على نفقة الشاكين، وذلك بعد سماع أقوال أعضاء مجلس الإدارة ومراجع الحسابات في جلسة خاصة، وإذا ثبت للجهة القضائية المختصة صحة الشكوى، جاز لها أن تأمر بما تراه من إجراءات تحفظية، وأن تدعو الجمعية العامة لاتخاذ القرارات اللازمة. ويجوز لها كذلك أن تعزل

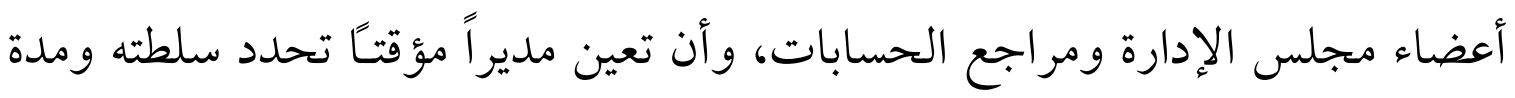
عمله (1) فالأصل أنه يجوز لوزارة الاقتصاد والهيئة والسلطة المختصة، كل في ما يخصه، حق مراقبة الشركات المساهمة والتفتيش على أعمالها ودفاترها أو أية أوراق أو سجلات لدى فروع الشركات وشركاتها التابعة داخل الدولة وخارجها، أو لدى مدقق حساباتها، أو لدى شركة أخرى ذات علاقة بالشركة محل التفتيش، ويجوز لها الاستعانة، مع لجنة التفتيش، بخبير أو أكثر من الجهات ذات الخبرة الفنية والمالية بموضوع التفتيش، للتحقق من قيامها بتنفيذ أحكام هذا القانون والقرارات الصادرة تنفيذاً له والنظام

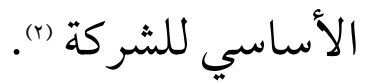
من ناحية أخرى، يجوز للمساهمين الحائزين على (• (1\%) على الأقل من رأس

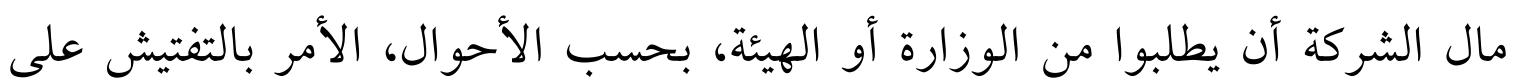
الشركة في ما ينسب إلى أعضاء مجلس الإدارة أو مدققي الحسابات من مخالفات جسيمة في أداء واجباتهم المقررة، بموجب أحكام القانون أو النظام الأساسي للشركة،

(1) المائة من نظام الشركات السعودي الصادر سنة VTV ا هجري. (Y) صالح عوض العقلا البلوي، الرقابة على أعضاء مجلس الإدارة في شركة المساهمة، مرجع سابق ، ص IVY . 
متى وُجد من الأسباب ما يُرجح وقوع هذه المخالفات.

ويجب أن يكون طلب التفتيش مشتملاً على الأدلة التي يُستفاد منها أن لدى لدى

الطالبين من الأسباب الجدية ما يبرر اتخاذ هذه الإجراءات. ويجب على المساهمين

مقدمي الطلب أن يودعو الأسهم التي يملكونها، وأن تظل مودعة إلى أن يتم الفصل في

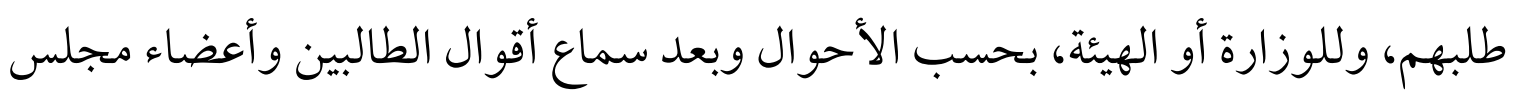
الإدارة أو من يقوم مقامه ومدققي الحسابات في جلسة سرية، أن تأمر بالتفتيش على أعمال الشركة ودفاترها أو أية أوراق أو سجلات لدى شركة أخرى ذات علات علاقة بالشركة

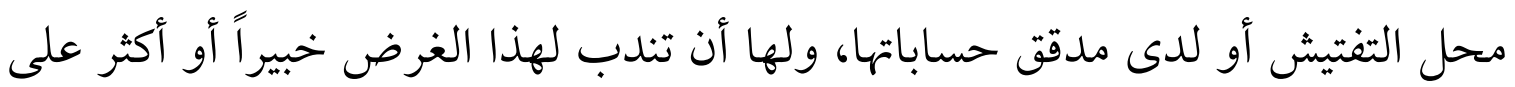
نفقة طالبي التفتيش (1).

(1) سليمان الجهني، ضوابط الرقابة على شركة المساهمة، مرجع سابق، ص 117. 


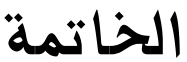

تناولت موضوع هذا البحث "الضواط النظامية للرقابة على إلى ماهية شركة المساهمة" من خلال مبحث تمهيدي ومبحثين رئيسيين، في المبحث الأول تناولت ماهية شركة المساهمة وذلك من خلال مطلبين، في المطلب الأول أوضحت مفهوم ونشأة شركة المساهمة، وفي والمطلب الثاني تناولت بالشرح أركان وأهمية شركة المساهمة، وفي المبحث الأول ناقشت مسؤولية مجلس إدارة شركة المساهمة من خلال ثلاث مطالب، المطلب الأول تناولت فيه مسؤولية أعضاء مجلس الإدارة تجاه الشركة، ثم في المطلب الثاني تطرقت إلى مسؤولية أعضاء مجلس الإدارة تجاه المساهمين، وفي المطلب الثالث تناولت بالشرح مسؤولية أعضاء مجلس الإدارة تجاه الغير، وفي المبحث الثاني ناقشت الرقابة الداخلية والخارجية على أعمال شركات المساهمة، وقد توصلت إلى النتائج و التوصيات الآتية:

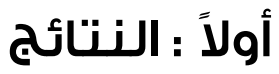
1 - إن مز اولة التجارة لا تقتصر على التجار فقط، وإنما تمتد لتمارس في إطار قانوني من قبل الأشخاص الاعتبارية وهي الشركات.

r- تقوم الهيئة العامة لسوق المال بالإشراف على السوق المالي، لذلك تقوم بتطوير السوق المالي، وإصدار التعليمات و القواعد المنظمة لسوق المال، وتقوم بالإشر اف المباشر على التأكد من تطبيق نظام السوق المالية. r- التفتيش على الشركات المساهمة يمكن أن يكون بأمر من القضاء بناء على طلب من أحد الساهمين ونصت المادة المائة من نظام الشركات السعودي الصادر سنة VIVV إهري على أن للمساهمين الذين يمثلون (0\%) على الأقل من رأس المال 
أن يطلبوا من الجهة القضائية المختصة الأمر بالتفتيش على الشركة إذا تبين لهم من تصرفات أعضاء مجلس الإدارة أو مراجع الحسابات في شؤون الشركة ما يدعو إلى الى الريبة.

\section{ثانياً : التوصيات}

1- ضرورة الرفع من الحد الأدنى لرأس مال شركة المساهمة حتى يسمح للشركة القيام بالمشاريع الضخمة التي هي مجال إختصاصها، من جهة و يكون ضمانًا كافيًا للدائنين من جهة أخرى. r- تبني الرأي الفقهي الذي نادى بأسبقية استيفاء الديون العادية لدائني الشركة عن ديون المساهمين في حالة تصفية شركة المساهمة، إذ أن إعطاء الأولية لديون عادية عن ديون الشركاء له ما يبرره في هذا المجال، وهو مسؤولية المساهمين في الوضع الذي آلت إليه الشركة، و من اللازم ترجمة ذلك في نص قانوني صريح يحمي دائني الشركة من المزاحمة في استيفاء الديون.

r- تشديد العقوبات على المخالفين من أعضاء مجلس إدارة شركة المساهمة، حيث

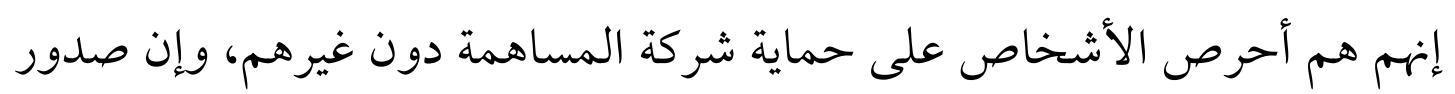
المخالفة منهم بمثابة تعدي صارخ على أمو ال الشركة و المساهمين. 


\section{قائمة المراجع}

I. د/ محمد محمود رزق، الرقابة على أعمال شركة المساهمة، بحث منشور بنك المعرفة المصري، المنصورة، 7 ا •ب، م .

Y. د/ عبدالهادي الغامدي، القانون التجاري السعودي، مجلة الشقيري، الطبعة الثانية، جدة، السعودية، VY أه الهري.

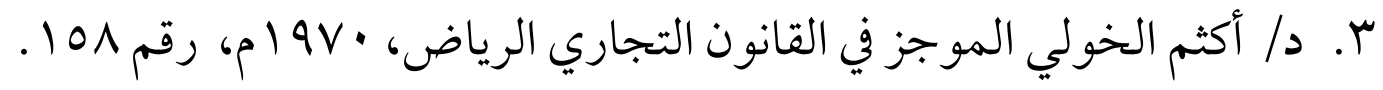
ع. د/ سمير عبد الحميد رضوان، أسواق الأوراق المالية ودورها في التنمية الاقتصادية، المعهد العالمي للفكر الإسلامي، القاهرة، ب.ت. ه. سعيد الكريدس ، جرائم الشركات التجارية في قوانين دول مجلس التعاون الخليجني. 7. دم/ فوزي عطوى: الشركات التجارية في القوانين الوضعية والشريعة الإسلامية،

$$
\text { منشورات الحلبي، لبنان، } 0 \text { • •. - م. }
$$

V. إبراهيم سيد أحمد ، الشركات التجارية في القانون السعودي ، المركز القومي للإصدارات القانونية ، القاهرة ، الطبعة الأولى 10 • ب م •

^. د د/ صالح بن زبن المرزوقي البقمي، شركة المساهمة في النظام السعودي، دراسة مقارنة بالفقه الإسلامي، جامعة أم القرى، الكتاب التاسع والثلاثون،

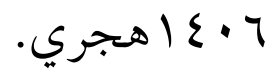

9 ـ. مرتضى نصر الله، الشركات التجارية ، مطبعة الإرشاد، بغداد 979 م. • ا ـ إدوار عيد، الشركات التجارية ( شركات المساهمة)، بيروت، مطبعة النجوى، 
1 ا . على حسن يونس، الشركات التجارية ( الشركات ذات المسؤولية المحدودة ، وشركات المساهمة والتوصية بالأسم )، القاهرة، مطبعة أبناء وهبه حسان. rا ـ سعيد يحيى، الوجيز في النظام التجاري السعودي، الطبعة الثانية، مطبعة المكتب العربي الحديث للطباعة والنشر، القاهرة، 10 • ب م.

سا ـ محمود محمد بابللي ، الشركات التجاري، الطبعة الأولى ، طبعة حلب ، سنة $.81 \% 91$

عا. د د/ حمدي محمود بارو د، أحكام القانون التجاري الفلسطيني، الشركات التجارية، الجزء الثالث، الطبعة الأولى ، ... ب ، غزة.

1 ا ـ د/ ثروت حبيب، دروس في القانون التجاري، الطبعة الأولى، القاهرة، ب . بم. 17 ـ ـ دلاح أمين أبو طالب، تجاوز السلطة في مجلس إدارة شركة المساهمة، دراسة مقارنة في القانون المصري والفرنسي، ط 1999 ، دار النهضة العربية. IV I. د. صالح البقمي، شركة المساهمة في النظام السعودي دراسة مقارنة بالفقـه الإسلامي: منشورات جامعـة أم القـرى، 7 • ع اهـ.

1 ا. سليمان الجهني، ضوابط الرقابة على شركة المساهمة، بحث ماجستير مقدم

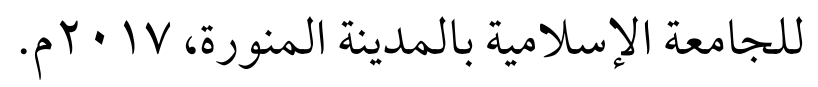
19 . صالح عوض العقلا البلوي، الرقابة على أعضاء مجلس الإدارة في شركة المساهمة، مكتبة القانون والاقتصاد الرياض، الطبعة الأولى، سبع ا هجري . الأنظمة و اللوائح

نظام الشركات السعودي (الجديد) الصادر بالمرسوم الملكي رقم (م / ؟) بتاريخ

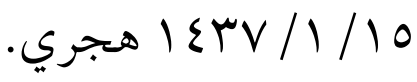


• نظام المحاسبين القانونيين الصادر المرسوم الملكي رقم(م/ Iا) وتاريخ

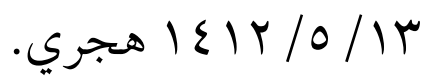

نظام السوق المالية الصادر بموجب المرسوم الملكي رقم (م / • ) بتاريخ

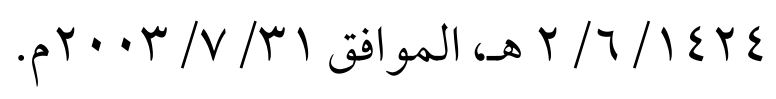

لائحة حوكمة الشركات الصادرة عن مجلس هيئة السوق المالية بموجب القرار

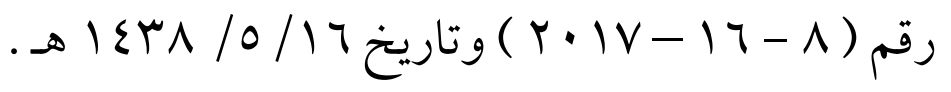

$$
\begin{aligned}
& \text { نظام الشركات الكويتي } \\
& \text { نظام الشركات الإماراتي } \\
& \text { نظام الشركات البحريني }
\end{aligned}
$$

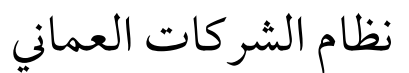




\section{فهرس الموضوعات}

$0 \cdot \varepsilon$

موجز عن البحث

0.0

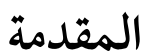

المبحث التمهيدي : ماهية شر كة المساهمة ونشأتها وأر كانها ........................ • • المطلب الأول : مفهوم ونشأة شركة المساهمة ...................................... المطلب الثاني : أهمية وأركان شركة المساهمة ..................................... ع 10 المبحث الأول : مسؤولية مجلس إدارة شر كة المساهمة ............................ rץ المطلب الأول : مسؤولية أعضاء مجلس إدارة الشركة المساهمة تجاه الشركة في ظل orr نظام الشركات السعودي المطلب الثاني : مسؤولية أعضاء مجلس إدارة الشركة المساهمة تجاه المساهمين في

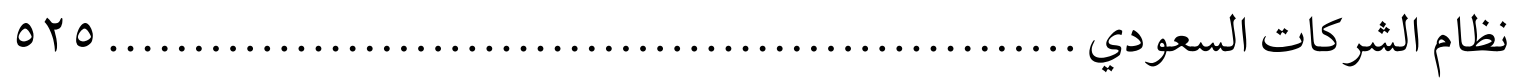
المطلب الثالث : مسؤولية أعضاء مجلس إدارة الشركة المساهمة تجاه الغير في ظل نظام

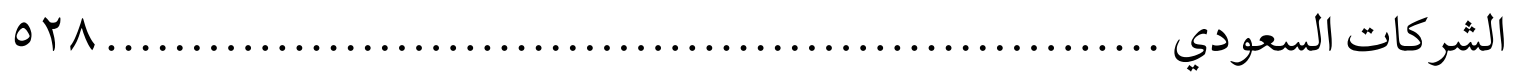
المبحث الثاني : الرقابة الداخلية والخارجية على أعمال شر كات المساهمة......... • بره or. المطلب الأول : أعمال الرقابة الداخلية. $0\{r$ المطلب الثاني : أعمال الرقابة الخارجية 00.

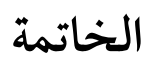

oOr قائمة المراجع 000 فهرس الموضوعات 